\title{
PRECISIONES SOBRE EL PODER DISCIPLINARIO DEL EMPLEADOR
}

\section{DETAILS ON THE DISCIPLINARY POWER OF THE EMPLOYER}

\author{
Raúl Fernández Toledo* \\ Universidad de Chile
}

\begin{abstract}
RESUMEN: Se exponen diversos aspectos dogmáticos del poder disciplinario del empleador con el propósito de precisarlo y evitar confusiones. Es así, que se trata: su fundamento, su naturaleza jurídica, su concepto y características, su finalidad, su relación con el poder de dirección, su relación con la responsabilidad contractual y una breve referencia a su regulación en el ordenamiento jurídico chileno.
\end{abstract}

Palabras clave: poder disciplinario, fundamento, poder de dirección, autotutela, falta laboral, sanción disciplinaria

ABSTRACT: there are exposed diverse dogmatic aspects of the disciplinary power of the employer in order to specify it and avoid confusions. Thus, the following aspects of the disciplinary power are treated: its foundation, its juridical nature, its concept and characteristics, its purpose, its relation with the power of direction, its relation with the contractual responsibility and a brief reference to its regulation in the juridical Chilean classification.

Key words: disciplinary power, foundation, power of direction, self governance, professional misconduct, disciplinary sanction

\section{INTRODUCCIÓN}

Cuando se habla del poder disciplinario del empleador se alude a la posibilidad que tiene el empleador de imponer sanciones a sus trabajadores que cometen faltas laborales. Por su parte, cuando se hace referencia al ejercicio del poder disciplinario, se está refiriendo a la imposición concreta de una sanción disciplinaria por parte del empleador o por quien lo represente al trabajador que comete una falta laboral.

Se está ante un poder que no existe en ninguna otra relación jurídica privada que comprenda la prestación de servicios personales, cuya característica esencial radica en la circunstancia que una de las partes tiene la facultad de imponer sanciones privadas a la otra parte, siendo el fundamento inmediato de ello la existencia de una relación laboral, que normalmente adopta la forma de contrato individual de trabajo, y el supuesto desencadenante la comisión de una falta laboral

\footnotetext{
Abogado. Licenciado en Ciencias Jurídicas y Sociales, Universidad de Concepción. Magíster en Derecho del Trabajo y Seguridad Social, Universidad de Talca - Universidad de Valencia. Instructor de Derecho del Trabajo, Facultad de Derecho, Universidad de Chile. Contacto: rfernandez@uchile.derecho.cl
} 
Raúl Fernández Toledo / Precisiones sabre el poder disciplinario del empleador

por el trabajador dependiente. De este modo, el contrato de trabajo es uno de los pocos contratos (seguramente el único contrato de prestación de servicios personales) en cuyo ámbito uno de los contratantes (el empleador) está dotado del poder de imponer a su partner contractual una pena privada ${ }^{1}$.

Constituye un poder que responde al carácter continuado de la prestación de servicios y a la voluntad del legislador de propinar estabilidad a la relación de trabajo ${ }^{2}$. Esto último porque no necesariamente se debe sancionar una falta laboral con la extinción del contrato de trabajo mediante el despido disciplinario, sino que es posible que se impongan al trabajador sanciones conservativas de la relación de trabajo, es decir, que no producen su extinción ${ }^{3}$. Estabilidad del contrato de trabajo que se justifica por dos argumentos, principalmente. De una parte, la extinción del contrato de trabajo mediante el despido disciplinario puede resultar en reiteradas ocasiones desproporcionada frente a incumplimientos laborales que no sean de una gravedad suficiente como para provocar la ruptura del vínculo contractual. De otra parte, si sólo pudiera despedirse al trabajador infractor, lo que sólo procede por incumplimientos laborales graves tipificados en el artículo 160 del Código del Trabajo, quedarían sin sanción los incumplimientos no graves, ocasionando un daño al empleador ese incumplimiento que no da lugar al despido disciplinario, además, de no producir un efecto negativo sobre el trabajador, con lo cual se incentivarían las conductas que constituyen incumplimientosde menor entidad ${ }^{4}$. Es en este contexto que se justifica el reconocimiento y ejercicio del poder disciplinario en el ámbito de las relaciones laborales ${ }^{5}$.

También responde el poder disciplinario al contexto en que se ejecuta la prestación de trabajo. Esto porque la relación laboral no se desarrolla aisladamente entre un empleador y un trabajador solamente, sino que habitualmente comporta la incorporación del dependiente a una organización empresarial que requiere de un trabajo en grupo, al tiempo que exige el mantenimiento de una disciplina en la empresa, de una relación de mutuo respeto entre los trabajadores ${ }^{6}$.

Debe tenerse presente que el poder disciplinario del empleador desde hace muchos años ha ocupado la atención de la doctrina extranjera, existiendo abundantes monografías al respecto. Atención que no ha sido similar en la doctrina nacional, que por muchos años hizo caso omiso sobre dicho poder del empleador. Tan sólo en el último tiempo han aparecido estudios del poder disciplinario en Chile?.

No obstante la preocupación de la doctrina nacional sobre el poder disciplinario, su dedicación ha sido especialmente sobre la configuración de la falta laboral ${ }^{8}$-que constituye el presupuesto de ejercicio del poder disciplinario- y sobre la sanción disciplinaria ${ }^{9}$-que es la concreción

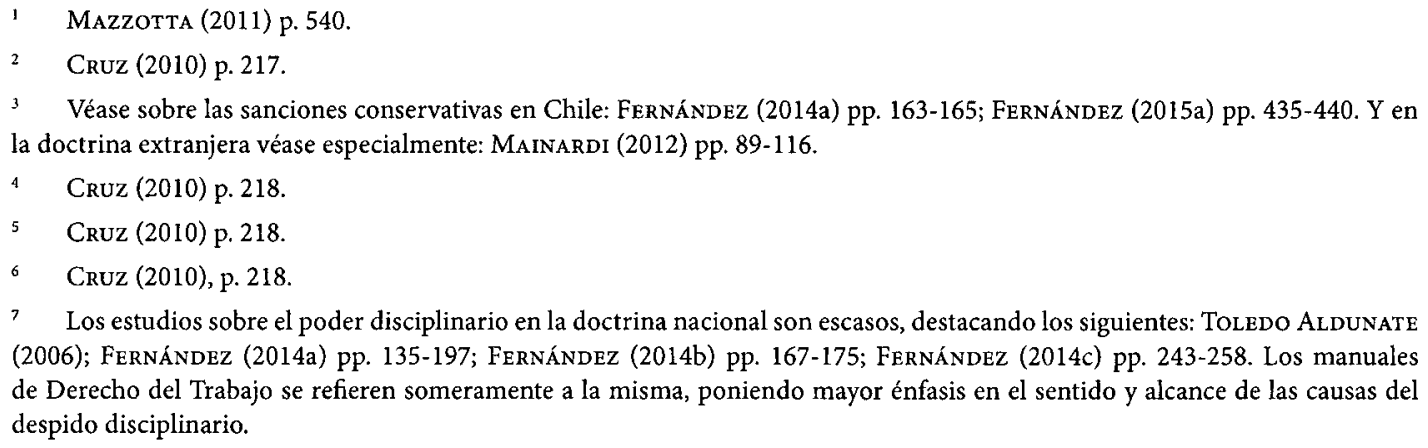


del poder disciplinario. Por lo que existen numerosos aspectos que no han sido tratados, o lo han sido someramente, cuales son: (i) fundamento y naturaleza jurídica del poder disciplinario; (ii) concepto y características; (iii) finalidad; (iv) relación entre el poder disciplinario y el poder de dirección; (v) relación entre la responsabilidad disciplinaria y la responsabilidad contractual y; (vi) regulación jurídica del poder disciplinario en el ordenamiento jurídico nacional ${ }^{10}$. De ahí, que el tratamiento en mayor detalle de los mismos es relevante para conocer la configuración dogmática del poder disciplinario, que permite evitar confusiones. También tiene como propósito servir de base para el tratamiento de las distintas fases del poder disciplinario y el procedimiento de impugnación de las sanciones disciplinarias que se imponen en virtud del ejercicio de aquél. Es por ello que dichos aspectos constituyen el objeto del presente artículo, para lo cual se recurrió a la doctrina extranjera, que se utiliza como argumento de refuerzo.

\section{FUNDAMENTO DEL PODER DISCIPLINARIO}

El surgimiento del poder disciplinario, según un reciente estudio de la historiografía francesa, se produce en el momento en que se separa el Derecho del Trabajo del Derecho Civil; la concepción del contrato como expresión de la libertad individual está en la base de la codificación napoleónica; en efecto, se fundaba en no consentir la existencia de un contrato que permitiera el dominio de una parte sobre la otra. En esta perspectiva, la subordinación se concebía, en sí misma, como poder de exigir una prestación acorde a lo convenido al momento de celebrar el contrato, primando una concepción del poder disciplinario como una suerte de cuerpo extraño respecto de la lógica de igualdad de intercambio entre dinero y prestación de servicios en el contrato liberal. En esta perspectiva, en la moderna empresa industrial se presentaba casi como el ejercicio de un mero poder de "facto"; poder que no podía encontrar una adecuada sistematización en el ámbito del contrato de trabajo original, desde que se limitaba a imponer al trabajador la forma de ejecutar sus labores.

Se suele indicar como el momento en que emerge una nueva concepción del contrato de trabajo el instante en que Corte de Casación francesa conoce de un caso, donde tuvo que decidir acerca de la legitimidad de una multa de 10 francos impuesta a un trabajador de uno de los primeros talleres, como consecuencia de su negativa a sacarse los zapatos antes de entrar al lugar donde la producción se estaba llevando a cabo. La solución que la Corte de Casación otorgó al caso a través de la sentencia de 14 de febrero de $1866^{11}$ se funda sobre la circunstancia que en el local de producción se publicó una reglamentación empresarial que imponía a los trabajadores (con un fin evidentemente de mayor higiene del local y de la producción) dejar sus calzados al exterior del lugar de producción. De aquí, el reconocimiento de parte del juez de un poder crediticio, dirigido a conformar la prestación del trabajador, en virtud del hecho que el trabajador se obligó al celebrar el contrato de trabajo no sólo a ejecutar la prestación sino también a las particulares condiciones necesarias para el desenvolvimiento de la actividad productiva, reconociéndosele al empleador el poder de sancionar unilateralmente la conducta que no respeta las condiciones prevista en el contrato de trabajo ${ }^{12}$.

\footnotetext{
Véase un breve resumen de estos aspectos en: FERnÁndez (2014 a) pp. 135-197.

LE GOFF (2004) p. 121.

Ferrante (2012) p. 2.
} 
Raúl Fernández Toledo / Precisiones sobre el poder disciplinario del empleador

Ahora bien, una de las grandes controversias en la doctrina, que perdura hasta el día de hoy, es determinar la razón de ser del poder disciplinario, esto es, cuál es el fundamento que justifica su existencia. Las posiciones se pueden resumir en tres: las que sostienen un fundamento contractual del poder disciplinario, las que defienden un fundamento institucional y las que postulan un fundamento heterónomo del poder disciplinario.

\subsection{FundAMENTO CONTRACTUAL DEL PODER DISCIPLINARIO}

Las teorías contractualistas parten de la base que el contrato de trabajo constituye la única fuente en que se fundamenta el poder disciplinario empresarial ${ }^{13}$. Sostienen fundado en la concepción liberal del contrato -que tiene sus raíces en el Código de Napoleón-que las partes mediante la autonomía de la voluntad pueden pactar el poder disciplinario en favor del empleador. De este modo, el empleador y el trabajador pueden establecer en el contrato de trabajo cláusulas, estableciendo y regulando el poder disciplinario, las que tendrán fuerza de ley entre las partes, limitándose la función de los tribunales de justicia a constatar el cumplimiento o incumplimiento de dichas estipulaciones. El poder disciplinario viene legitimado en cuando se le reconozca por las partes mediante su regulación en el contrato de trabajo, aun cuando se conceda al empleador la facultad de regularlo a través de normas internas elaboradas unilateralmente por él, porque de todas formas su fundamento último es el contrato de trabajo.

Así las cosas, de acuerdo a la teoría contractualista es la autonomía de la voluntad el mecanismo que explica el nacimiento y subsistencia de un poder privado que autoriza al empleador a imponer sanciones disciplinarias a sus trabajadores dependientes por infracciones a obligaciones y prohibiciones contractuales o establecidas en reglamentos de régimen interior, sin intervención previa de un juez y en ausencia del principio de igualdad entre las partes contratantes, propio de las concepciones liberales del contrato. En esta concepción del poder disciplinario las sanciones disciplinarias hacen nacer una responsabilidad disciplinaria de carácter contractual para el trabajador infractor, cuya regulación se remite al derecho común de las obligaciones ${ }^{14}$. Por tanto, la legitimidad de las sanciones deriva del acuerdo entre las partes, sea expresa o tácita, y el ejercicio del poder disciplinario se vincula al régimen de ejecución del contrato ${ }^{15}$.

Las deficiencias de esta concepción contractual del poder disciplinario son varias, desde que presenta una serie de inconsistencia que la hacen inviable para considerarla un fundamento real del poder disciplinario. En primer lugar, debido a que de acuerdo a la misma el poder disciplinario nace porque se pacta en el contrato de trabajo, es decir, el empleador se erige en titular de este poder sancionador debido a que el trabajador acepta limitar su propia voluntad individual, no logra explicar cuál es el fundamento del poder del disciplinario cuando no existe contrato de trabajo por escrito o bien no contiene una estipulación expresa que reconozca este sistema sancionador ${ }^{16}$. Lo que perfectamente puede suceder en nuestro sistema jurídico, porque la escrituración del contrato de trabajo no es una solemnidad para su nacimiento, sino solamente una formalidad de prueba (artículos 8 y 9 del Código del Trabajo), o bien, que constando por escrito no contenga estipulaciones sobre el poder disciplinario, más aun cuando la regulación de dicho poder no es

\footnotetext{
RoDríguez (2008) p. 1.

RODRÍGUEZ (2008) p. 2.

GIL (1993) p. 47; RodríGUEZ (2008) p. 2.

RODRÍGUEZ (2008) p. 2.
} 
una de las exigencias mínimas del contenido del contrato individual de trabajo (artículo 10 del Código del Trabajo).

En segundo término, debido a que la facultad de sancionar deriva de cada contrato individual de trabajo, se corre el riesgo que se produzcan desigualdades entre los distintos trabajadores, pudiendo originarse una situación discriminatoria entre los mismos, lo que no es admisible en el Derecho del Trabajo actual ${ }^{17}$.

En tercer lugar, la tesis contractual clásica no puede explicar la ampliación del campo de acción de la responsabilidad disciplinaria sobre faltas laborales cometidas respecto de compañeros de trabajo, que no son parte del contrato individual de trabajo, sino que son terceros. No puede justificar por qué las agresiones o insultos a compañeros de trabajo son causa de una sanción disciplinaria, puesto que tales conductas no constituyen un incumplimiento contractual ${ }^{18}$. Si bien la disciplina laboral no sólo impone al trabajador obligaciones respecto del empleador, que es la otra parte de la relación laboral, sino también respecto de los demás trabajadores, que son terceras personas desde el punto de vista contractual, no puede encontrar su fundamento en el contrato de trabajo el poder disciplinario respecto de faltas laborales cometidas hacia compañeros de trabajo, al ser terceros ajenos al contrato de trabajo ${ }^{19}$.

Igualmente, parte de un supuesto falso, desde que se fundamenta en la igualdad de las partes del contrato de trabajo, libres para estipular lo que estimen conveniente a sus intereses, lo que claramente no ocurre, porque el empleador se encuentra en una situación de supremacía respecto del trabajador al momento de la negociación del contrato ${ }^{20}$. Circunstancia que provoca la imposición de las cláusulas por parte del empleador, que impide apreciar el contrato de trabajo desde la óptica del derecho común de las obligaciones. La concepción contractual olvida que el Derecho del Trabajo surgió, precisamente, por la evidente debilidad contractual del trabajador frente al empleador, estableciendo derechos mínimos irrenunciables en favor del dependiente.

Por otro lado, la naturaleza contractual del poder disciplinario puede generar diversos inconvenientes indeseados. El principal, es que la intervención judicial se ve limitada por las propias estipulaciones del contrato de trabajo que regulan el poder sancionador. La libertad del empleador para establecer faltas y sanciones disciplinarias escapa al control del juez, al no poder entrar a valorar la proporcionalidad entra la falta laboral y la sanción disciplinaria aplicada, debiendo sólo determinar si las faltas laborales y sanciones están permitidas por el contrato de trabajo, como también si existe correspondencia entre ambas estipulada contractualmente ${ }^{21}$.

Debido a las inconsistencias de la tesis contractual clásica, surgieron posiciones más modernas, que intentan superar las deficiencias que presenta la teoría clásica. Una de estas variantes contractuales modernas es la denominada teoría del "contrato organización", que permite superar ciertas deficiencias de la tesis contractual clásica. Fundado en la subordinación, sostiene que ésta proporciona al empleador los medios necesarios para lograr la ejecución de la prestación de trabajo debida en el conjunto de las demás prestaciones, introduciendo una dimensión organizativa en la relación individual ${ }^{22}$. Desde el punto de vista del trabajador, la obligación de trabajar no consiste solamente en ejecutar la prestación de trabajo debida, consiste, además, en una colaboración

\footnotetext{
17 Gil (1993) p 47; RodríGuez (2008) p. 2.

18 Gil (1993) p. 48.

19 Gil (1993) p. 48.

20 Rodríguez (2008) pp. 2-3.

21 Rodríguez (2008) p. 2.

22 FernáNdez (1991) p. 35.
} 
Raúl Fernández Toledo / Precisiones sobre el poder disciplinario del empleador

para la obtención del objetivo propuesto por el empleador: ejecutar la prestación para el logro de aquél fin, "incluyendo en ella todas las obligaciones conectadas con el buen funcionamiento de la organización, porque todas esas obligaciones aseguran la colaboración adecuada que satisface el interés del acreedor y, por tanto, todas ellas -aun las más acusadamente disciplinarias- son reconducibles al contrato, al cumplimiento del contrato" (Fernández, 1991, p. 36).

El contrato de trabajo es instrumental a los objetivos del empresario y, por ello, se pone al servicio de la organización empresarial, proporcionando al empleador los instrumentos técnicos que permiten asegurarle y conformarle a sus exigencias a través de los poderes empresariales que quedan encajados en el contrato y de las subordinación del trabajador a éstos, porque forma parte del cumplimiento del contrato, y no deriva de obligaciones externas a él ${ }^{23}$.

Cada vez son más quienes conciben como elementos integrantes del contrato de trabajo aspectos perfectamente reconducibles a exigencias organizativas, modulando los derechos y obligaciones de las partes ${ }^{24}$. Las exigencias organizativas se integran en el contrato de trabajo, y si "la sumisión del trabajador a ellas no viene impuesta por razones diversas de la propia naturaleza de su prestación -que es una prestación de trabajo subordinado- no hay razones para no reconducir al contrato el fundamento último del poder disciplinario, máxime si tampoco las consecuencias prácticas que de ello derivan son tan dramáticamente diferentes como las primeras formulaciones hacían pensar" (Fernández, 1991, p. 38).

De acuerdo a esta concepción, el contrato de trabajo no desempeña, como lo hacía en un principio, una función meramente legitimadora, mediante la justificación de las facultades sancionadoras a través de un pacto expreso convenido entre las partes. Las explicaciones contractuales iniciales únicamente tendían a introducir la ficción formal de la voluntad del afectado como explicación de la limitación de la libertad del trabajador, mediante la admisión de un sistema sancionador contractual. Sin embargo, el contrato de trabajo no cumple esa función, sino que constituye un marco adecuado en el que ha de desenvolverse el poder, centrando en el trabajo pactado el ejercicio del mismo, restringiendo su campo de actuación. La función del contrato de trabajo ha dejado de ser legitimadora para pasar a asumir una función racionalizadora, porque el reconocimiento del poder disciplinario es un elemento esencial en el contrato, que no depende de un pacto expreso para existir, pero sometido a la lógica y a las exigencias de la relación que une a las partes y, que compromete al trabajador en el correcto desenvolviendo de la organización ${ }^{25}$. En otros términos, el poder disciplinario es de la esencia del contrato de trabajo, no necesitando de estipulación expresa para su existencia, pero sujeto a los requisitos propios del contrato de trabajo.

La teoría del contrato organización si bien, supera todas las dificultades de la tesis contractual clásica, se le formula como crítica que al configurar el contrato de trabajo como un contrato organización se extiende desmesuradamente el objeto del contrato, hasta el punto de equiparar el objeto con el contenido del contrato, lo que dogmática no es admisible, al ser conceptos diferentes ${ }^{26}$.

\subsection{FUNDAMENTO INSTITUCIONAL DEL PODER DISCIPLINARIO}

Como una reacción a la teoría contractual se procuró recurrir a otras alternativas para superar las deficiencias que presentaba, siendo una de ellas la teoría de la institución, que fun-

\footnotetext{
23 Fernández (1991) pp. 36 - 37

24 FERNÁNDEZ (1991) p. 37.

25 FERnÁNDEZ (1991) pp. 38-39.

26 GIL (1993)p. 49.
} 
damenta la razón de ser del poder disciplinario. La teoría de la institución presenta la innegable importancia que permite superar el escollo de la legitimidad del poder disciplinario no expresamente pactado, que no logra explicar la teoría contractual clásica. La sentencia de la Corte de Casación francesa de 16 de junio de 1945 es uno de los mayores hitos jurisprudenciales de la teoría en cuestión. En el caso que conoció, un trabajador fue suspendido de empleo y de sueldo durante una semana por desobediencia, no obstante que en su contrato de trabajo no se había pactado nada sobre la eventual posibilidad de imponer sanciones y en la empresa en cuestión no existía tampoco un reglamento interno para suplir la deficiencia. La Corte de Casación sostuvo la licitud de la sanción impuesta, porque "esta circunstancia no puede, en efecto, privar al patrón de un poder disciplinario inherente a su cualidad, y del que tiene la facultad, en ausencia de disposiciones restrictivas de un Reglamento de Régimen Interior, de hacer uso bajo la reserva de control de la autoridad judicial" (Droit Social, 1946, p. 427). Según se puede observar "La Corte parece afirmar la existencia de un poder disciplinario ligado a la calidad de empresa [...] que le separa de la voluntad de las partes para vincularlo a la existencia del cuerpo social" (Vennin, 1973, p. 37).

La teoría institucional vincula el poder disciplinario al empleador por su calidad de jefe de la organización productiva, se trata de un poder originario, "que se genera por el hecho mismo de la existencia de una colectividad organizada y que le sitúa en manos de quien dirige la organización para que la organización misma pueda alcanzar su fin" (Fernández, 1991, p. 37).

Un clásico autor italiano partidario del institucionalismo, Santi Romano, sostiene que el régimen jurídico del Estado no es capaz de regular adecuadamente el ámbito de la empresa, ya sea por una imperfección no deseada, por una limitación que se impone a sí mismo o por la pervivencia de disposiciones antiguas para regir la vida moderna. De ahí, que tales instituciones creen "un ordenamiento jurídico propio, interno, distinto del que les ha sido atribuido por el Estado, y que muchas veces no se limita sólo a integrar este último, sino que se contrapone a él con un contraste que, aunque disimulado, no por ello deja de ser menos evidente" (Romano, 1945, p. 227), siendo uno de los ejemplosmás claros de dicha tendencia -a su juicio-el poder disciplinario empresarial. Agrega, que "siempre que se da un organismo social de cierta complejidad, aunque sea pequeña, se instaura en su interior una disciplina que contiene todo un ordenamiento de autoridad, de poderes, de normas y de sanciones" (Romano, 1945, p. 228). Añade que "toda comunidad, ya sea una fábrica o un establecimiento, una empresa o una escuela, un convictorio o, incluso, un círculo de recreo, tiene necesidad absoluta de estos reglamentos internos de carácter disciplinario" (Romano, 1945, p. 228).

La teoría institucional presenta una gran ventaja en relación a la teoría contractual clásica, superando los obstáculos planteados en los casos en que el contrato de trabajo no contiene disposiciones acerca de la existencia del poder disciplinario, además, presenta ventajas pragmáticas, que pueden sintetizarse, siguiendo a Camerlynck:

“a)Teniendo por fin la represión de la violación por el trabajador de sus deberes hacia la comunidad profesional de la que forma parte y, que compromete su buen funcionamiento, el poder disciplinario va progresivamente a organizarse y limitarse. El poder devendrá derecho disciplinario.

b) Concerniente a los conflictos provocados por el ejercicio del poder disciplinario, el juez tendrá por misión verificar, además, de la regularidad formal de la medida disciplinaria, su correcto fundamento y la ausencia de desviación de poder" (Fernández, 1991, pp. 28-29). 
Raúl Fernández Toledo / Precisiones sobre el poder disciplinario del empleador

La teoría institucional se basa en una concepción comunitaria o corporativa del contrato de trabajo, alude a la idea de la consecución de un fin común, para cuya consecución han de colaborar empleador y trabajadores, y que justifica la atribución originaria de los poderes de organización al jefe de la empresa, a fin de que ésta pueda alcanzar aquél fin. Igualmente, la noción de institución conduce a dicha conclusión, desde que la misma "pide como complemento, como columna vertebral de la organización, la idea de un fin común, para el que cooperen todos sus miembros, en el que se fundan todos los poderes internos, para cuya consecución se conceden" (Fernández, 1991, p. 30). Situación que no se condice con la noción de empresa actual, que es propiedad exclusiva del empleador, siendo él el titular de los medios de producción y de los beneficios obtenidos con la actividad económica que desarrolla, para lo cual se le conceden ciertos poderes, entre ellos, el poder disciplinario.

Tampoco resulta admisible una concepción armónica y comunitaria de las relaciones laborales en el modelo de relaciones laborales de hoy en día. Como afirma Kahn-Freund es una pura utopía el hecho de postular una comunidad de intereses como sustrato de las relaciones laborales ${ }^{27}$. Agrega el gran jurista inglés:

“excavar las raíces de esta utopía de la armonización preestablecida entre empresarios y trabajadores sería una tarea fascinante para un sociólogo; éste probablemente descubrirá doctrinas basadas en el laissez-faire junto a una cruda variante de marxismo y con toda certeza las (más o menos espurias) construcciones ideológicas utilizadas por Mussolini para apuntalar el Stato Corporativo, y asimismo, podría observar cómo la utopía puede degenerar en el falso romanticismo de aderezos feudales que empleó Hitler en su legislación laboral" (Kahn-Freund, 1983, p. 64).

Concluye Kahn-Freund sus reflexiones preliminares sobre el derecho y el poder, afirmando que sea cual sea el origen y el uso de las doctrinas comunitaristas, las mismas han de rechazarse, pues "el conflicto entre capital y trabajo es consustancial a la sociedad industrial y, por ello, a las relaciones laborales; las normas pueden tratar de resolver los conflictos, pero no eliminarlos" (Kahn-Freund, 1983, p. 65).

La doctrina comunitaria es incompatible con el modelo democrático de las relaciones laborales, que reconoce la libertad de empresa y la libertad sindical, el derecho a la negociación colectiva y la existencia misma del conflicto en la empresa. El conflicto y la diversidad de intereses entre la parte empleadora y la parte trabajadora es consustancial a las relaciones laborales. De ahí, que la tesis institucional no pueda ser considerada como fundamento del poder disciplinario en el actual sistema de relaciones laborales.

\subsection{FUNDAMENTO HETERÓNOMO DEL PODER DISCIPLINARIO}

La concepción que parece más acertada como fundamento del poder disciplinario es la que sostiene que el mismo halla su fundamento mediato en la ley e inmediato en el contrato de trabajo, en que la ley actúa como fuente de integración del contrato de trabajo. Tal poder posee relevancia no sólo respecto del objeto del contrato, sino también en lo tocante al contenido del contrato ${ }^{28}$.

\footnotetext{
27 Kahn-Freund (1983) p. 64.

28 Gil (1993) p. 49.
} 
Si bien el poder disciplinario nace como consecuencia de la celebración del contrato de trabajo, formando parte de la esencia del mismo, no tiene sólo una fuente contractual, sino también legal. Circunstancia que justifica que el empleador pueda sancionar faltas laborales que atentan contra la integridad de compañeros de trabajo, que no son parte del contrato. Para ello, según Galgano es preciso distinguir el objeto del contenido del contrato, aun cuando en doctrina se confunda a menudo las dos nociones; el objeto consiste en las prestaciones mediante las que se persigue lograr el fin económico-social del contrato; por el contrario, el contenido es la regulación contractual (regolamento contrattuale), el conjunto de cláusulas que las partes prevén o que se insertan en el contrato en virtud de una fuente de integración del contrato (la ley, los usos y la equidad, en el derecho italiano, según lo dispuesto en el art. 1.374 del codice civile $\left.{ }^{29}\right)^{30}$.

El contenido del contrato es "la resultante de una pluralidad fuentes, una sola de las cuales es el acuerdo de las partes" (Galgano, 1990a, p. 142). En nuestro derecho, es el artículo 1546 del Código Civil el que expresa esta pluralidad de fuentes de la regulación contractual, cuando ordena que quien contrata queda obligado contractualmente, no sólo a lo consentido sino " $a$ todas las cosas que emanan precisamente de la naturaleza de la obligación, o que por la ley o la costumbre pertenecen a ella". Dicha norma, de aplicación supletoria a la relación laboral, permite distinguir entre el objeto y el contenido del contrato de trabajo, no siendo necesario establecer una diferencia ulterior.

El objeto del contrato de trabajo abarca solamente la prestación de servicios del dependiente en forma subordinada ${ }^{31}$. La prestación personal del dependiente, característica del contrato de trabajo se reduce a la obligación de trabajar, y hacerlo bajo las órdenes del empresario atinentes a la ejecución del contrato ${ }^{32}$. Sin embargo, los poderes de dirección y disciplinario permiten imponer al trabajador obligaciones que exceden del puro objeto contractual, y que suponen una ampliación del deber básico de trabajar de forma subordinada, debido a que el trabajo se ejecuta en una organización ${ }^{33}$, en que intervienen diversas personas, adquiriendo una relevancia trascendental el reglamento interno. No forman parte del objeto contractual ciertas obligaciones, deberes y prohibiciones por el sólo hecho de prestar servicios en una organización productiva. Así sucede con las obligaciones y prohibiciones a que deben sujetarse los trabajadores, en relación con su permanencia y vida en las dependencias de la respectiva empresa o establecimiento, en que juega una función esencial el reglamento interno dictado en virtud de la ley, desde que "especialmente, se deberán estipular las normas que se deben observar para garantizar un ambiente laboral digno y de mutuo respeto entre los trabajadores" (artículo 153 inciso $2^{\circ}$ del Código del Trabajo). El trabajador debe observar una serie de obligaciones y prohibiciones que miran el respecto y buen trato con sus compañeros de trabajo, quienes son terceros desde un punto de vista estrictamente contractual. El interés organizativo del empleador excede el objeto del contrato de trabajo. Al poseer éste una dimensión colectiva, conlleva ciertas obligaciones que exceden el marco estrictamente contractual, y que sólo pueden hallar su fundamento en una de las fuentes de carácter heterónomo que

\footnotetext{
29 En el caso chileno la ley, la naturaleza del contrato y la costumbre, de acuerdo al artículo 1546 del Código Civil. Tratándose de la ley, integra el contenido del contrato y también faculta al empleador elaborar normas internas, como el reglamento interno, que le permiten ejercer el poder disciplinario.

30 Galgano (1990a) p. 189.

31 Gut (1993) p. 52.

32 GiL (1993) p. 52.

33 GrL (1993) p. 52.
} 
Raúl Fernández Toledo / Precisiones sobre el poder disciplinario del empleador

menciona el artículo 1546 del Código Civil -la ley, la costumbre y la buena fe - la que actuará especificando y ampliando obligaciones que se derivan del hecho de prestar servicios a otra persona.

El trabajador se encuentra obligado a cumplir diversas obligaciones que tienen fuentes diversas, de manera que el fundamento unitario del poder disciplinario no puede ser nunca solamente el contrato, sino una fuente heterónoma de integración del $\mathrm{mismo}^{34}$, entre las que se incluye la ley, la que engloba la negociación colectiva y el reglamento interno.

El poder disciplinario actúa tanto sobre el objeto del contrato de trabajo como sobre su contenido. Es así, que fuentes externas al contrato de trabajo actúan como fuente de integración del contenido del contrato de trabajo en virtud del artículo 1546 del Código Civil.

Confirma el fundamento heterónomo del poder disciplinario, que no todas las obligaciones que debe observar el trabajador son necesariamente contractuales. Así ocurre con el reglamento interno, el que no forma parte del contrato de trabajo ${ }^{35}$, pero que no obstante integra el contenido del contrato, y permite imponer sanciones conservativas del contrato de trabajo por infracción a las obligaciones y prohibiciones contenidas en el mismo en que incurren los trabajadores. Si sólo tuviera un fundamento contractual el poder disciplinario no se justifica cómo puede imponer el empleador sanciones a trabajadores por infracción a obligaciones no contractuales. Si se puede es porque la ley lo permite, lo que revela que el contrato de trabajo se complemente mutuamente con la ley, constituyendo el fundamento principal del poder disciplinario.

Como consecuencia de la procedencia del ejercicio del poder disciplinario frente a infracciones de obligaciones que no forman parte del contrato de trabajo, la responsabilidad disciplinaria no es necesariamente contractual, excediendo el puro ámbito contractual.

\section{NATURALEZA JURÍDICA DEL PODER DISCIPLINARIO}

Junto con el fundamento otra cuestión que corresponde determinar dice relación con establecer cuál es la naturaleza del poder disciplinario, lo que lleva a responder la pregunta ¿qué es el poder disciplinario? Una de las posiciones más aceptadas hoy en día es que el poder disciplinario es, a la vez, un acto de autotutela privada y derecho subjetivo potestativo.

\subsection{Calificación del EJERCicio del POder disciplinario COMO ACTO DE AUTOTUTE- LA PRIVADA}

En el ámbito privado rige el principio de heterotutela, según el cual los particulares deben someter sus controversias de relevancia jurídica a los tribunales de justicia, siendo un tercero imparcial quien resuelve los conflictos jurídicos. De permitirse a los particulares hacer justicia por

34 GiL (1993) p. 53.

35 Gamonal y Guidi (2012) p. 97: "el reglamento interno no forma parte ni se incorpora al contrato de trabajo, dado que emana unilateralmente de la voluntad del empleador. Incluso, si luego de su dictación se firmara un anexo incorporándolo al contrato, esta incorporación adolecerá de un manto de duda, porque el trabajador subordinado difícilmente podrá oponerse. Por tanto, su incorporación no podrá contener estipulaciones leoninas ni disminuir las cláusulas previamente convenidas entre las partes". En sentido contrario se ha sostenido: "Su carácter de fuente del derecho ha sido reconocido por fallos de los tribunales, los cuales incluso le han dado una característica que la ley no senala, cual es la de pasar a ser parte integrante del contrato individual de trabajo. La Corte Suprema en un fallo de 1977 señaló que "los reglamentos internos forman parte de los contratos individuales de trabajo $y$, por lo mismo, si en ellos se prohíbe expresamente determinadas negociaciones relativas al giro del negocio, quien la transgrede incurre en la causal del artículo $156 \mathrm{~N}^{\circ} 2$ del Código del Trabajo" - hoy, del artículo $160 \mathrm{~N}^{\circ} 2$ ", LANATA (2010) pp. 38-39. 
mano propia la fuerza sustituiría al derecho y la seguridad jurídica se vería comprometida gravemente. Es por ello que cada vez que una persona considere lesionado un derecho o interés legítimo debido a la conducta de otro sujeto debe recurrir a los tribunales de justicia a fin que se restablezca el imperio del derecho mediante una decisión con autoridad de cosa juzgada. Es el ejercicio de la jurisdicción el que permite corregir el ordenamiento jurídico alterado y solucionar los conflictos entre particulares. Tal como indica García de Enterría:

"cualquier sujeto que pretenda alterar frente a otro la situación de hecho existente (statu quo) no puede hacerlo por su propia autoridad; si el otro sujeto no aceptase de grado esa alteración, tiene la carga de someter su pretensión a un Tribunal, el cual la valorará desde la perspectiva del Derecho y la declarará conforme o no con éste, dándole en el primer caso fuerza ejecutoria, esto es, una virtud especial que la hace indiscutible y de cumplimiento forzoso para la parte obligada" (García de Enterría, 1974, p. 60).

Por otro lado "si esa resolución ejecutoria no fuese cumplida de grado, tampoco el sujeto beneficiado con la misma podrá imponerla a la otra parte por su propia coacción privada, sino que deberá impetrar el respaldo coactivo mediante una segunda pretensión dirigida al Tribunal, el cual dispondrá la asistencia de la coacción pública (única legítima) si se acredita que, en efecto, la resolución que trata de imponerse goza de fuerza ejecutoria" (García de Enterría, 1974, p. 60).

Sin embargo, excepcionalmente el ordenamiento jurídico faculta, en ciertos supuestos, a los particulares defender su propio interés sin que intervenga previamente un juez. Uno de ellos es la autotutela privada, que se puede definir como "el poder concreto, reconocido expresamente por la ley, que habilita a defender el propio interés mediante un acto o negocio jurídico unilateral y extrajudicial" (Gil, 1993, p. 20). Cinco son las notas esenciales que caracterizan la autotutela: la existencia de un poder concreto, no general; la fuente legal del poder; la defensa de un interés propio; adopta la forma de acto o negocio jurídico unilateral; y la falta de intervención previa del juez ${ }^{36}$.

Posee un carácter excepcional, desde que la regla general es que los tribunales de justicia solucionen las controversias con relevancia jurídica, por tanto, precisa de un reconocimiento legal explícito. El ordenamiento jurídico prohíbe la autotutela, por lo que para que proceda es necesario una habilitación legal expresa. Debido al carácter excepcional de la autotutela privada no existe en nuestro Derecho un poder general que faculte a defender directamente los propios intereses a los particulares. La autotutela privada es un poder concreto que la ley reconoce y afecta situaciones específicas, no estando admitida la autotutela general.

Como consecuencia del carácter excepcional de la autotutela privada, requiere necesariamente de una cobertura legal, requiriéndose de "un reconocimiento legal explícito" (García de Enterría y Fernández, 1989, p. 497). La misma es siempre legal, aun cuando los pactos y normas unilaterales integren y complementen el supuesto de hecho de autotutela previsto en la ley ${ }^{37}$. En efecto, hay casos en que la ley permite que las partes realicen un pacto o una de ellas elabore normas unilateralmente, actuando como presupuesto causal del poder de autotutela que reconoce aquélla.

\footnotetext{
36 GiL (1993) p. 20.

37 GiL (1993) p. 26.
} 
Raúl Fernández Toledo / Precisiones sobre el poder disciplinario del empleador

Por medio de la autotutela privada los particulares defienden un interés propio, esto es, de derechos, intereses o situaciones de ventaja que el ordenamiento les reconoce ${ }^{38}$. Son excepcionales las hipótesis de autotutela en que se autoriza a un particular defender un interés ajeno.

La autotutela privada se exterioriza mediante un acto jurídico unilateral el cual produce una modificación directa sobre el plano sustancial ${ }^{39}$. El acto jurídico en sentido estricto representa el instrumento normal de realización de la autotutela privada ${ }^{40}$.

Característica de la autotutela privada es, igualmente, la falta de intervención previa del juez. La autotutela importa autodefensa y autoprotección, y postula la reafirmación extrajudicial de un interés propio ${ }^{41}$. "A diferencia de la jurisdicción, la autotutela no tiene como finalidad la satisfacción de una pretensión, sino la defensa de un interés lesionado o en peligro o, en otras palabras, el mantenimiento del orden jurídico existente" (Gil, 1993, p. 31).

La autotutela no es definitiva, sino sólo previa o inicial, puesto que la ley reserva al juez la competencia de analizar a posteriori la legalidad del acto que la exterioriza. Si la parte respecto de la cual se ejerció impugna el acto, el juez será competente para controlar la legalidad de la autotutela privada ${ }^{42}$.

El análisis de los elementos configuradores de la autotutela radica en determinar si en el ejercicio del poder disciplinario concurren o no todos los requisitos configuradores de la autotutela privada, porque dependiendo de ello, se establece si es o no un supuesto de autotutela privada. La conclusión es que el ejercicio del poder disciplinario empresarial es un acto de autotutela privada, desde que concurren todas las notas características determinantes de la autotutela privada.

El ejercicio del poder disciplinario constituye una forma de autotutela privada de carácter activo, en cuanto reclama una conducta positiva de parte del empleador, que tiene como resultado la mutación de las cosas; además, posee un carácter reactivo ${ }^{43}$, ya que reacciona el empleador contra la comisión previa de una falta laboral del trabajador, constituyendo el presupuesto de actuación del ejercicio del poder disciplinario.

Se pueden resumir de la siguiente forma como concurren los elementos característicos de la autotutela privada en el ejercicio del poder disciplinario: El ordenamiento jurídico reconoce al empleador principalmente en los artículos 154 números 10,11 y 12, 160 y 162 del Código del Trabajo un poder concreto de aplicar y ejecutar unilateralmente sanciones disciplinarias; con ello el empleador defiende un interés propio - el normal desenvolvimiento de la actividad productiva y la disciplina laboral - a través de un acto jurídico unilateral (forma que adoptan las sanciones disciplinarias) y sin la intervención previa del juez como regla general ${ }^{44}$.

\footnotetext{
38 Dagnino (1983) p. 48 ss.

39 GiL (1993) p. 29.

40 BigliazZi (1971) pp. 66-67.

4) Gil (1993) p. 31.

12 Gil (1993) p. 32.

43 Gil (1993) p. 33; PoQuet (2011) p. 22: "podemos sostener que el poder disciplinario se trata de una especie de autotutela, por medio de la cual se defiende un interés propio, y se ejerce en forma unilateral, sin la presencia previa de un juez, ya que equivale a una autodefensa o autoprotección [...]. Por ello, la calificación del ejercicio del poder disciplinario como supuesto de autotutela privada sirve para resaltar que el negocio jurídico del empresario produce sus efectos en el plano sustancial, modificando o extinguiendo la relación laboral, sin que sea necesaria la intervención previa del juez".

44 GiL (1993) p. 33; PoQuet (2011) p. 22.
} 


\subsection{CALIFICACIÓN DEL EJERCICIO DEL PODER DISCIPLINARIO COMO DERECHO POTESTA- TIVO}

Los artículos $154 \mathrm{~N}^{\circ} 10$ y 160 del Código del Trabajo reconocen en favor del empleador un poder concreto, que se activa frente a incumplimientos en que incurren los trabajadores. Pues bien, el ejercicio del poder disciplinario constituye un derecho potestativo.

En la doctrina es vivamente discutido el concepto de derecho potestativo, ni siquiera se han logrado los autores poner de acuerdo acerca del nombre más apropiado que debería dársele. Pero pese a estas objeciones el concepto de derecho potestativo resulta útil para determinar la naturaleza del poder disciplinario. El autor italiano Galgano destaca que ciertas normas no imponen deberes o prohibiciones, sino que configuran una situación de sujeción: el sujeto ha de soportar, de forma pasiva, las consecuencias del acto ajeno. El concepto de poder designa "la situación activa, correlativa a una sujeción" (Galgano, 1990b, p. 28), ya venga reconocida por el derecho público o por el derecho privado. A los poderes que reconoce el derecho privado se les da normalmente el nombre de derechos potestativos ${ }^{45}$.

Una de las definiciones de derecho potestativo que puede adoptarse es la de Larenz, para quien el derecho potestativo "es aquél que habilita a una persona a establecer una relación jurídica con otra, o a determinarla específicamente en su contenido, modificarla o extinguirla mediante un acto constitutivo unilateral que es, por lo común, una declaración de voluntad"(Larenz, 1978, p. 281). Al derecho potestativo "corresponde por parte del otro, el oponente de ese derecho, una vinculación, debido a la cual éste ha de aceptar y tolerar la modificación jurídica y la irrupción de su propia esfera jurídica" (Larenz, 1978, p. 282). En virtud de los derechos potestativos "su titular queda facultado para influir sobre situaciones jurídicas preexistentes, modificándolas, extinguiéndolas o creando otras nuevas, y todo ello mediante una unilateral declaración de voluntad y sin que frente a la misma corresponda una verdadera obligación de otro sujeto, sino más bien un estado de sujeción" (Diez-Picazo y Gullón, 2004, p. 420). Los mismos "se ejercen mediante un acto jurídico y tienen la característica de que no dan derecho a la conducta ajena, de modo que no tienen como contrapartida un preciso deber jurídico. Corresponden a competencias o potestades que el orden jurídico confiere a las personas para crear, modificar o extinguir relaciones jurídicas privadas" (Bourie, 2006, p. 618).

Si se tiene presente la noción de derecho potestativo expuesta no hay dificultad para calificar como derecho potestativo al ejercicio del poder disciplinario empresarial. Las sanciones disciplinarias modifican o extinguen, de forma unilateral, la relación laboral, según sean conservativas o extintivas del contrato de trabajo. Es así, como la amonestación y la multa desmejoran la posición jurídica del trabajador, sancionando sin extinguir el contrato de trabajo, en cambio, el despido disciplinario extingue el contrato de trabajo.

En la doctrina extranjera se califica el ejercicio del poder disciplinario como un derecho potestativo, especialmente la española, destacando Rivero Lamas ${ }^{46}$, Fernández López ${ }^{47}$ y Gil y Gil ${ }^{48}$.

En consecuencia, resulta claro que el ejercicio del poder disciplinario es un supuesto de autotutela privada que adopta la forma de derecho potestativo.

45 GIL (1993) p. 35.

46 GiL (1993) p. 35.

47 RIVERo (1986) pp. 83-84.

18 FernándeZ (1991) p. 42 nota 53 


\section{CONCEPTO DEL PODER DISCIPLINARIO Y CARACTERÍSTICAS}

Expuesto el fundamento y naturaleza jurídica del poder disciplinario se está en condiciones de precisar los contornos del mismo y sus características esenciales.

No existe una definición legal de lo que debe entenderse por poder disciplinario, a pesar de presuponer la existencia de una relación laboral. Las normas legales se limitan esencialmente a establecer las sanciones disciplinarias que puede imponer el empleador a sus trabajadores y el presupuesto de las mismas: la infracción de obligaciones y prohibiciones laborales, siendo las normas principales los artículos $154 \mathrm{~N}^{\circ} 10,157$ y 160 del Código del Trabajo. Situación que no es propia y peculiar del ordenamiento jurídico nacional, debido a que el en derecho comparado tampoco existe una definición del poder disciplinario, lo que obliga a recurrir a la doctrina.

Muchas han sido las definiciones que se han dado por la doctrina sobre el poder disciplinario, siendo todas, eso sí, coincidentes en su contenido esencial. Así, se le ha conceptualizado como "la facultad que ostenta el empresario para imponer sanciones a los trabajadores como consecuencia de la realización por parte de éstos de conductas que impliquen un incumplimiento de la relación y la disciplina laboral" (Carcelén, 2001,p. 22). En similares términos, pero colocando más énfasis en el fundamento inmediato de ejercicio: el contrato de trabajo, se le ha definido como "el conjunto de facultades derivado del contrato, que posibilita al empresario para imponer sanciones como reacción frente al incumplimiento de las obligaciones asumidas por los trabajadores en el seno de la relación de trabajo" (Fernández, 1991, p. 68).

Es así, como la causa que desencadena el ejercicio concreto del poder disciplinario es la conducta imputable al trabajador cometida durante la ejecución del contrato de trabajo, que se encuentra señalada como falta o prohibición en el reglamento interno de la empresa, de existir dicho instrumento $o$, bien, en el contrato de trabajo y/o en algún instrumento colectivo de trabajo. Es necesario para su materialización concreta una falta o incumplimiento laboral. Afirmación de la cual derivan tres consecuencias. La primera, que mientras el trabajador no incurra en un incumplimiento a las obligaciones asumidas a través de su contrato de trabajo, o en infracción a las obligaciones y prohibiciones señaladas en el reglamento interno, no podrá ser sancionado por el empleador. La segunda, estrechamente vinculada con la anterior, es que cada trabajador solamente puede ser sancionado por las faltas por él cometidas, no pudiendo ser castigado por conductas imputables a otros trabajadores, debido a que se trata de una responsabilidad personalísima ${ }^{49}$. Y la tercera, que el trabajador solamente puede ser sancionado por la acción u omisión en que incurre mientras se desempeña como subordinado en su calidad de dependiente. El empleador no lo puede sancionar por la conducta que tiene fuera de la relación laboral, cuando ya ha terminado su jornada de trabajo, por estar en un ámbito personal que escapa al control empresarial, en la medida que dicha conducta no afecte el cumplimiento de las obligaciones laborales.

No obstante lo indicado, se presenta el problema de determinar si se pueden considerar como infracciones laborales las conductas externas a la empresa o que dicen relación con la vida privada del trabajador. La regla general es que no es posible considerar como falta laboral situaciones extra-laborales, que no tienen incidencia en el desenvolvimiento de la relación laboral ni en el cumplimiento de las obligaciones que impone al trabajador. Las mismas no pueden constituir el fundamento de una sanción laboral. Para que ello suceda es necesario que provoquen un

49 BRÉgOU (2012) p. 40. 
incumplimiento de una obligación o prohibición laboral del trabajador ${ }^{50}$, como puede ocurrir por ejemplo con una condena penal privativa de libertad por un delito cometido fuera de la empresa, caso en el cual el trabajador puede ser despedido por inasistencias injustificadas, por no poder concurrir al trabajo por una conducta imputable a él.

La titularidad del poder disciplinario radica en el empleador, el cual, tratándose de personas jurídicas, será ejercido por quienes tengan facultades generales de administración o bien por las personas que ejerzan funciones de supervisión y fiscalización en el trabajo. Dicha facultad de imponer sanciones en forma unilateral constituye una excepción al principio de reserva a favor de los poderes públicos del ejercicio del poder sancionador, en el sentido, de que, salvo este poder a favor del empresario, ninguna otra persona o entidad, excepto los poderes públicos, pueden sancionar por incumplimientos contractuales sin acudir, previamente, a los tribunales de justicia, sanciones que, además, deberán ser cumplidas por los trabajadores, sin perjuicio de que quepa su posterior control judicial. El mantenimiento y garantía del orden en las relaciones laborales así lo requiere, no siendo conveniente imponerlas a instancias de un órgano externo a la empresa, por cuando el incumplimiento laboral de un trabajador requiere de una respuesta inmediata a la infracción laboral, lo que no ocurriría de esperarse trámites de terceros, que sin duda se dilatarían en el tiempo.

La única excepción a la imposición y auto ejecución de las sanciones laborales está constituida por el despido disciplinario de los trabajadores que gozan de fuero laboral, debido a que el empleador no puede despedir al trabajador aforado luego de cometida un falta laboral que configura alguna de las causales de caducidad establecidas en el artículo 160 del Código del Trabajo. Es necesario para ello solicitar autorización al juez laboral competente a través de un juicio de desafuero (artículo 174 del Código del Trabajo), y sólo una vez concedida la autorización, se puede despedir válidamente al trabajador. De no existir autorización judicial, el despido del trabajador que goza de fuero laboral adolece de un vicio que lo hace anulable absolutamente, cual es objeto ilícito (artículos 10, 1466 y 1682 del Código Civil y 174 del Código del Trabajo).

Como características del poder disciplinario se pueden señalar varias, destacando las que se indican a continuación. En primer lugar, se trata de un poder instrumental ${ }^{51}$, al dotar al empresario de un instrumento necesario para garantizar el correcto desarrollo de la relación de trabajo, así como asegurar que la conducta de los trabajadores no ponga en peligro el ciclo productivo de la empresa ni los medios de producción, siendo importante para ello establecer una tipificación previa de las obligaciones y prohibiciones que deben observar en el trabajo, como también las sanciones a que se hallan expuestos. Si al empleador mediante el poder de dirección se le confiere la facultad de organizar y dirigir la actividad productiva, el poder disciplinario, en su facultad de sancionar, constituye un mecanismo útil para garantizar la efectividad del poder de dirección, y con ello la buena marcha de la actividad empresarial, evitando, o en su caso, reprimiendo las conductas que puedan alterarla ${ }^{52}$. No tiene mucho sentido hablar del poder disciplinario, como un poder diferenciado e independiente de los demás de que está dotado el empleador. Inserto en

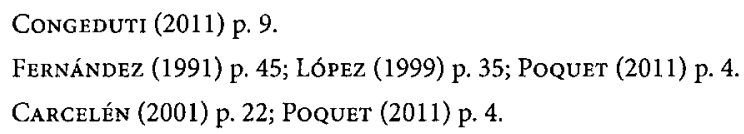


Raúl Fernández Toledo / Precisiones sobre el poder disciplinario del empleador

la relación de trabajo aparece como un derecho secundario del poder de dirección, siendo una consecuencia jurídica de éste $e^{53}$. Incluso, algunos le han considerado parte del poder de dirección ${ }^{54}$.

En segundo lugar, se puede calificar como un poder jerárquico ${ }^{55}$, debido a que es una consecuencia de la posición de superioridad que posee el empleador frente a los trabajadores, quienes se encuentran en una posición de dependencia y subordinación. Esta desigualdad fue la que provocó el origen del Derecho del Trabajo, el cual introdujo una serie de límites a la posición de jerarquía del empleador, y con ello a las facultades que derivan de la misma, entre las que se encuentra el poder disciplinario, el cual debe observar una serie de límites en su ejercicio.

Asimismo, se trata de un poder discrecional ${ }^{56}$, lo que significa que el empleador puede decidir ejercitarlo o no ejercitarlo, aun cuando se den los supuestos de hecho de las infracciones o incumplimientos labores, que autorizan la imposición de alguna sanción laboral. De este modo, si dos o más trabajadores incurren en similares infracciones, el empleador puede sancionar a unos y a otros no, al gozar de discrecionalidad. Sin embargo, debe ser cauteloso en su actuar discrecional, porque en su ejercicio no puede imponer a algunos trabajadores sanciones discriminatorias, sea por razones sindicales, de sexo, religión, entre otras, por ser un derecho de los trabajadores que constituye un muro infranqueable para los derechos del empleador. Tratándose del despido, el derecho a la no discriminación no puede ser quebrantado, pues de hacerlo será calificado de vulneratorio del mismo, pudiendo el empleador ser condenado con la reincorporación del trabajador, siendo nulo el despido, o bien con la indemnización tarifada establecida en el artículo 489 del Código del Trabajo (artículo 489 inciso $4^{\circ}$ del Código del Trabajo). Lo mismo ocurre con el despido antisindical, que es una modalidad especial de despido discriminatorio (artículo 294 del Código del Trabajo).

La discrecionalidad en el ejercicio del poder sancionador del empleador es una nota distintiva frente al ius puniendi estatal, debido a que los órganos públicos dotados del mismo están obligados a sancionar siempre que se den los presupuestos legales, en cambio, el empleador no está obligado a sancionar en todo caso, sino sólo si así lo estima conveniente, aunque se dieren los supuestos para ello ${ }^{57}$. La razón de esta diferencia radica en que los órganos del Estado que están dotados del ius puniendi sirven a los intereses públicos, no pudiendo dejar de cumplir sus funciones, bajo pena de ser objeto de fuertes sanciones, mientras que el empresario sirve a sus propios intereses, que son privados ${ }^{58}$. El ius puniendi estatal opera en el campo del derecho público, y el poder del empresario en el contexto del derecho privado.

Debido a lo anterior, se trata de un poder cuyo ejercicio está sujeto a control ${ }^{59}$ judicial, tratándose del despido y de las sanciones conservativas, con excepción a la multa, cuyo control en su imposición corresponde a la Inspección del Trabajo competente (artículo 157 del Código del Trabajo). El contenido de los artículos 168, 420 letra a) y 489 del Código del Trabajo, no dejan

53 FERNÁNDEZ (1991) p. 45.

54 Dirección del Trabajo (2002) Ord. N² 2856/162, disponible en: http://www.dt.gob.cl/legislacion/1611/w3-article-96717. html [fecha de vista 10 de marzo de 2015]; Dirección Del Trabajo (2009) Ord. N²210/035, disponible en: http://www.dt.gob. cl/legislacion/1611/w3-article-96717.html [fecha de vista 10 de marzo de 2015]; Doudchitzky con MerlinTelecommunications Chile S.A. (2013).

55 Carcelén (2001) p. 23; Poquet (2011) p. 4.

56 POQUET (2011) p. 5.

57 Carcelén (2001) p. 24; Poquet (2011) p. 5.

58 CARCELÉn (2001) p. 24; Poquet (2011) p. 5.

59 CARCELÉN (2001) pp. 25-26. 
lugar a dudas del control que los tribunales de justicia realizan del poder disciplinario, una vez que se impone una sanción laboral. Constituye una garantía para el trabajador sancionado, en tanto que la impugnación judicial de la sanción se produce cuando ésta ya ha sido efectivamente impuesta e, incluso, se está cumpliendo. El control no sólo se limita a la existencia o inexistencia de la falta imputada al trabajador, sino que también se extiende a la valoración de la falta de haberse cometido, de tal forma que, atendiendo a la gravedad de los hechos puede ser considerada de excesiva la sanción aplicada. El control provocará, tratándose de las sanciones conservativas, que sean dejadas sin efecto por el órgano del Estado competente, y respecto del despido disciplinario, que sea declarado injustificado, con la excepción del despido discriminatorio, el despido disciplinario antisindical y el despido de personas aforadas sin autorización judicial previa, que pueden ser dejados sin efecto cuando no se respetan los límites del poder disciplinario.

Además, cabe calificarlo como un poder limitado, en el sentido que no se trata de un poder absoluto, por el contrario, su ejercicio está sometido a límites tanto materiales como formales, que pueden tener su origen tanto en la ley como en el contrato de trabajo o instrumento colectivo de trabajo e, incluso, en el reglamento interno ${ }^{60}$. Todavía más, dichos límites puede emanar de la propia naturaleza del poder disciplinario, lo que es especialmente relevante en el ordenamiento laboral, donde gran parte de los límites no se encuentran señalados por el legislador, haciéndolos desprender los Tribunales de Justicia del carácter sancionador del mismo. Gozan de este status el principio nos bis in idem, el principio de proporcionalidad, el principio de legalidad y tipicidad, los cuales tienen una función esencial tanto en la configuración de la falta laboral, que es el supuesto inmediato que desencadena el ejercicio del poder disciplinario, como en la configuración y determinación de la sanción disciplinaria que puede imponer el empleador.

Se trata de un poder de ejecución inmediata, característica que le permite al empleador imponer sanciones a los trabajadores infractores con eficacia inmediata, sin necesidad de acudir a instancias judiciales o administrativas para su imposición y efectividad, siendo su contrapartida el correlativo derecho del trabajador, además, de otras garantías, de obtener en la vía judicial o administrativa, dependiendo de la sanción impuesta, la revisión de la conformidad a Derecho de la decisión empresarial ${ }^{61}$. Esto significa que el trabajador debe comenzar a cumplir la sanción desde el día señalado en la comunicación efectuada por el empleador como fecha de efectos, sino que pueda negarse a su imposición, ya que la sanción y su cumplimiento no necesitan la aquiescencia del trabajador sancionado ni de ninguna autoridad. La función de los órganos del Estado es revisar la sanción impuesta, dejarla sin efecto, cuando sea procedente, o bien condenar al empleador al pago de las indemnizaciones correspondientes, cuando la sanción no puede ser anulada, lo que ocurre con el despido por regla general. Lo señalado tiene una excepción, la que está constituida por el despido disciplinario de los trabajadores con fuero laboral, debido a que para que los mismos puedan ser despedidos válidamente es necesario que un juez competente autorice previamente el despido.

\section{FINALIDAD DEL PODER DISCIPLINARIO}

El fin del poder disciplinario se encuentra más cercano a los instrumentos de sanción y castigo que a los mecanismos de reparación del daño propios de la responsabilidad civil, pues en

60 CARCELÉN (2001) pp. 26-27.

61 Carcelén (2001) pp. 27-28; Poquet (2011) p. 20. 
Raúl Fernández Toledo / Precisiones sobre el poder disciplinario del empleador

virtud de su ejercicio se imponen verdaderas penas privadas ${ }^{62}$. La insuficiencia en esta materia de los mecanismos civiles de resolución por incumplimiento y de la indemnización por daños provocó la recepción del sistema sancionador. El Derecho del Trabajo tomando como fuente de inspiración la construcción penal de los delitos y las penas y, en las administrativas de las contravenciones y sanciones, establece un sistema de faltas y sanciones laborales ${ }^{63}$, a las que tratan de aplicarse, salvando las distancias y con muchas matizaciones, los principios característicos de las sanciones públicas, como son los de legalidad y tipicidad, non bis in idem y de proporcionalidad ${ }^{64}$.

La responsabilidad disciplinaria no se dirige a resarcir el daño que pudiere haber sufrido el empleador con el actuar indebido del trabajador, por lo demás, no es requisito de existencia para la configuración de una falta o incumplimiento laboral, pudiendo estar o no presente. Su finalidad última es el mantenimiento del orden y buen funcionamiento de la empresa, diferenciándose de la responsabilidad civil, que tiene como fin la reparación de un daño. Dicho objetivo se consigue, primero, defendiendo este mismo orden antes que sea quebrantado, por conminación, por la amenaza de sanciones disciplinarias a los posibles infractores, siendo necesario para ello la tipificación previa de las faltas laborales y sanciones en los instrumentos que ha establecido la legislación para ello. El fin del poder disciplinario, en este primer momento, es alejar del ambiente de trabajo la comisión de faltas laborales, es evitar que los trabajadores incurran en infracciones, ejecutando su trabajo correctamente. Después que el orden haya sido quebrantado, el poder disciplinario cumple una finalidad de segundo grado, y es el de restituir el orden a su primitivo estado o bien evitar nuevas faltas laborales en el futuro, mediante la aplicación y ejecución de sanciones disciplinarias $^{65}$.

Su finalidad una vez cometida la infracción laboral es fundamentalmente punitiva, teniendo, a la vez, una capacidad represiva, correctiva y preventiva, dependiendo de la naturaleza de la sanción aplicada. En primer término, el poder disciplinario tiene como finalidad básica el castigo del trabajador por las conductas o infracciones cometidas, finalidad que alcanza su mayor expresión en la multa y el despido disciplinario, donde el trabajador se ve privado de bienes jurídicos valiosos para él. En la multa de parte de su remuneración diaria y en el despido de su contrato de trabajo, que en la generalidad de los casos constituye la única fuente de ingreso para el trabajador y su familia, de ahí, que sea la máxima sanción posible de aplicar al trabajador. Por ello ha sido reservado por el legislador para los incumplimientos laborales graves, algunas de los cuales han sido objetivados, dejando escaso margen de discrecionalidad al empleador, mientras que otros han sido establecidos con mayor amplitud, donde el margen de actuación del empleador es mayor, sin perjuicio del posterior control judicial.

En segundo lugar, el poder disciplinario cumple una función de reeducación o reinserción del trabajador castigado, pues con la imposición de la sanción no sólo se pretende castigar, sino también hacer ver al trabajador que su conducta no es conforme con el actuar que debe observar en la ejecución de la relación laboral, debido a que perjudica la marcha de la empresa y, en ocasiones el trabajo, salud o integridad de sus compañeros ${ }^{66}$. Este objetivo alcanza mayor notoriedad en las sanciones conservativas del contrato de trabajo, que son la mayoría existentes en el ordenamiento jurídico (amonestación verbal, amonestación escrita y multa), las cuales por su propia

\footnotetext{
62 Poquet (2011) p. 23; Mazzotta (2011) p. 540.

63 Fernández-Costales (2005) p. 39.

61 Poquet (2011) p. 23.

65 José de Mesquita citado por Poquet (2011) pp. 23-24.

66 POQUeT (2011) p. 24.
} 
naturaleza son eminentemente correctivas más que punitivas. Incluso más, se ha sostenido por parte de la doctrina que el fin del poder disciplinario es eminentemente correctivo y no punitivo ${ }^{67}$, debiendo ofrecer el empresario al trabajador la posibilidad que enmiende su comportamiento, abandonando su comportamiento ilícito antes de sufrir el despido disciplinario. El fin principal del poder disciplinario es correctivo, siendo el despido disciplinario la última ratio, siendo este el criterio sostenido por la OIT en los instrumentos existentes sobre la materia ${ }^{68}$.

Los trabajados previos a la elaboración del Convenio 158 y de la Recomendación 166 de la OIT aluden a la obligación de hacer una advertencia antes de proceder al despido. El informe VIII del año 1981 sostiene que dicho requisito "tiene por objeto dar al trabajador la ocasión de mejorar su conducta o desempeño antes de sufrir una sanción radical como el despido, a menos que el quebrantamiento de la disciplina sea de tal magnitud que no pueda esperarse que la relación de trabajo prosiga" (citado por Gil, 1993, p. 115).

Finalmente, cumple una finalidad preventiva general, debido a que con el ejercicio del poder disciplinario el empleador muestra su disposición a sancionar determinados comportamientos que pueden afectar a la marcha de la empresa, lo que permite a los demás trabajadores tomar conocimiento y adquirir conciencia de cuál es la reacción del empleador frente a las faltas laborales que cometan algunos de ellos ${ }^{69}$. De esta forma, la imposición de una sanción previene la comisión de nuevas faltas laborales, disuadiendo de su comisión futura tanto al trabajador sancionado como a los demás trabajadores. Tiene una función intimidatoria respecto de la generalidad de los trabajadores, al buscar prevenir ulteriores violaciones de la normativa disciplinaria y de las normas de conducta que tutelan la organización productiva empresarial ${ }^{70}$.

En la función asignada a la pena disciplinaria se advierte una cierta distancia con la sanción civil-resarcitoria, por cuando la sanción disciplinaria tiene una función aflictiva frente al incumplimiento, además, de intimidatoria y preventiva con el propósito de garantizar la disciplina en el interior de la empresa y de regular la conducta a observar en la organización productiva. De ahí, que se observe una cierta analogía entre la sanción disciplinaria y la penal en cuanto a su función, pero con importantes diferencias, siendo la más relevante el interés tutelado ${ }^{71}$ (público en la sanción penal y privado en la sanción laboral).

Al tener la naturaleza de penas privadas, las sanciones laborales siempre van a tener una finalidad preventiva especial y general ${ }^{72}$. No se altera su naturaleza con el hecho que algunas sanciones laborales -el despido disciplinario- provoquen la extinción de la relación laboral, pues las

\footnotetext{
67 Mazziotti (1982) p. 135; Gil (1993) p. 114.

68 Dicha afirmación quedaría corroborada con lo dispuesto en el artículo 7 de la Recomendación 166 de la OIT, que señala "no debería darse por terminada la relación de trabajo de un trabajador por una falta cuya índole, en virtud de la legislación o la práctica nacional, sólo justificaría la terminación en caso de reincidencia una o varias veces, a menos que el empleador haya prevenido por escrito al trabajador de manera apropiada". El Convenio 158 de la OIT, al que está vinculado la Recomendación 166 , no ha sido ratificado por el Estado de Chile, por lo que no forma parte del ordenamiento jurídico nacional, sin perjuicio que tanto el mismo como la recomendación 166 deban ser tenidos en consideración en su calidad de norma mínima internacional. RoJAs (2013) p. 111.

69 POQUeT (2011) pp. 24-25.

70 MaINARd (2002) p. 170. La sanción disciplinaria en su fin intimidatorio general no mira tanto a restablecer el equilibrio alterado con la falta laboral ni a promover un retorno al estado de las cosas anterior a la falta, sino evitar que se repita la conducta castigada, sea por el mismo trabajador o por sus compañeros de trabajo. En este sentido: MAINARDI (2002) p. 170.

71 Mainardi (2002) p.26.

72. RODRÍGUEZ (2008)p 183.
} 
Raúl Fernández Toledo / Precisiones sobre el poder disciplinario del empleador

sanciones privadas no se limitan a las medidas conservadoras de la relación laboral en que se insertan, sino que también son posibles las resolutorias del contrato ${ }^{73}$.

La doctrina y jurisprudencia italiana ${ }^{74}$ confirma la pluralidad de funciones de la responsabilidad disciplinaria, al considerar que tiene una duplicidad de funciones, por un lado aflictiva y de prevención especial respecto del trabajador que cometió la infracción sancionada y, por otro lado, intimidatoria y de prevención general respecto de los demás trabajadores de la empresa, que es la función típica y peculiar de la sanción disciplinaria.

\section{LA RELACIÓN ENTRE EL PODER DISCIPLINARIO Y EL PODER DE DIRECCIÓN}

El poder de dirección es "el conjunto de facultades jurídicas a través de cuyo ejercicio el empresario dispone del trabajo realizado por su cuenta y a su riesgo, ordenando las singulares prestaciones laborales y organizando el trabajo en la empresa" (Montoya, 1965, p. 44). Conforme a esta definición el poder de dirección se manifiesta a través de una pluralidad de actos y comprende diversas facultades, concretando los deberes del trabajador a través de órdenes singulares sobre la prestación de trabajo y las coordina para conseguir el fin económico - técnico de la empresa.

Tiene un carácter obligatorio desde que se ejerce con carácter imperativo, "ya que este poder genera un auténtico deber de obediencia en el trabajador" (Román, 1992, p. 109). Mediante el ejercicio del poder de dirección el empleador dispone del trabajo prestado por su cuenta, ordenando las singulares prestaciones laborales y organizando el trabajo en la empresa. El contenido de éste poder es muy amplio y variado, comprendiendo tanto funciones ordenadoras (órdenes e instrucciones) y funciones de decisión sobre la organización de la empresa ${ }^{75}$.

Contribuyen a garantizar la efectividad del poder de dirección otros poderes de que está dotado el empleador, como son el poder de control y vigilancia y el poder disciplinario. De este modo, el poder de dirección y el poder disciplinario están muy relacionados, de manera, que se sostiene por la doctrina, que el segundo actúa como la consecuencia penal de la trasgresión del primero por parte del trabajador ${ }^{76}$.

El poder disciplinario constituye así el complemento ideal e imprescindible del poder de dirección, debido a que este último sería un "mero poder moral" (Olea y Casas, 2006, pp. 425- 426) sino se permitiera al empleador sancionar los incumplimientos a los órdenes generales y especiales que imparte a sus trabajadores. El poder disciplinario así encuentra su justificación, la razón de existir, constituyendo uno de los medios más eficaces para garantizar el orden organizativo de la empresa $y$, en último término, el fin productivo de aquélla ${ }^{77}$.

No obstante su estrecha vinculación existe una clara distinción entre ambos poderes; al ser el poder disciplinario instrumental al poder de dirección, actuando cuando este último ha resultado lesionado, no pueden confundirse. El poder de dirección permite imponer órdenes,

\footnotetext{
FERNÁNDEZ (1991) p. 236.

Congenuti (2011) p. 11.

Montoya (2014) p. 366.

Rodríguez (2008) p. 16.

Monstuschi (1973) p. 10; Terradillos (2004) p. 16.
} 
mientras que el poder disciplinario permite imponer sanciones: No es una distinción formal, sino de contenido, hay una verdadera separación por el objeto ${ }^{78}$.

A pesar de la clara distinción entre el poder de dirección y el poder disciplinario la jurisprudencia administrativa incluye dentro del concepto amplio de poder de dirección al poder disciplinario. Es así, que la Dirección del Trabajo ha señalado:

"Al empleador le es reconocido el ejercicio de una serie de facultades o prerrogativas que tienen por objeto el logro del referido proyecto empresarial en lo que al ámbito laboral se refiere, y que se traducen en la libertad para contratar trabajadores, ordenar las prestaciones laborales, adaptarse a las necesidades de mercado, controlar el cumplimiento y ejecución del trabajo convenido, y sancionar las faltas o los incumplimientos contractuales del trabajador. Estas facultades, que responden a lo que genéricamente se denomina poder de dirección -comprendiendo en este concepto amplio tanto el poder de dirección strictu sensu como el disciplinario"79.

De este modo, para la Dirección del Trabajo en un concepto amplio del poder de dirección se comprenden todas las facultades y poderes de que está dotado el empleador, incluyendo el poder disciplinario y, solamente, en un concepto restringido de poder de dirección distingue el poder de dirección del poder disciplinario. Esa es, también, la opinión sostenida por un sector de la doctrina comparada, para quien el poder sancionatorio del empleador forma parte de las facultades que integran el poder de dirección; configuración unitaria que es brindada, en su concepto, por el reconocimiento constitucional del derecho de la libertad de empresa ${ }^{80}$. Se agrega que los

$78 \quad$ Montoya (1965) pp. 142-143.

79 Dirección Del Trabajo (2002) Ord. N² 2856/162, disponible en: http://www.dt.gob.cl/legislacion/1611/w3-article-96717. html [fecha de vista 10 de marzo de 2015]; Dirección del Trabajo (2009) Ord. N²210/035, disponible en: http://www.dt.gob. $\mathrm{cl} /$ legislacion/1611/w3-article-96717.html [fecha de vista 10 de marzo de 2015]. Otros dictámenes tampoco le reconocen una autonomía propia al poder disciplinario. Así ha sostenido la Dirección del Trabajo "mientras el sistema jurídico dota al empleador de lò que la doctrina llama el poder de dirección y de disciplina, esto es, de la facultad para dirigir y mantener el orden dentro de la empresa, que de alguna manera es manifestación de los derechos constitucionales de propiedad y de la libertad para desarrollar cualquier actividad económica, dicha facultad se encuentra jurídicamente limitada por las garantías constitucionales dirigidas a proteger la dignidad y honra de las personas" (Dirección Del Trabajo (1996) Ord. Nº 287/14, disponible en: http://www. dt.gob.cl/legislacion/1611/w3-article-96717.html [fecha de vista 10 de marzo de 2015]; Dirección DeL Trabajo (1995) Ord. $\mathrm{N}^{\circ}$ 8005/323, disponible en: http:/www.dt.gob.cl/legislacion/1611/w3-article-96717.html [fecha de vista 10 de marzo de 2015]). Igualmente, ha señalado "la doctrina uniforme y reiterada de este Servicio, en relación con las atribuciones de mando, dirección y administración de la empresa, que corresponden al empleador, dentro de las cuales estaría implícita la potestad disciplinaria y sancionadora" (Dirección Del Trabajo (1987) Ord. N 2084/104, disponible en: http://www.dt.gob.cl/legislacion/1611/w3article-96717.html [fecha de vista 10 de marzo de 2015]; Dirección Del Trabajo (2001) Ord. $\mathrm{N}^{\circ}$ 3659/0180, disponible en: http:/www.dt.gob.cl/legislacion/1611/w3-article-96717.html [fecha de vista 10 de marzo de 2015]). También la Dirección del Trabajo ha indicado que el poder de dirección está constituido por "una serie de facultades o prerrogativas que tienen por objeto el logro del referido proyecto empresarial en lo que al ámbito laboral se refiere, y que se traducen en la libertad para contratar trabajadores, ordenar las prestaciones laborales, adaptarse a las necesidades del mercado, controlar el cumplimiento y ejecución del trabajo convenido, y sancionar las faltas o los incumplimientos contractuales del trabajador"(DIRECCIÓN DEL Trabajo (2002) Ord. No 2856/162, disponible en: http://www.dt.gob.cl/legislacion/1611/w3-article-96717.html [fecha de vista 10 de marzo de 2015]; Dirección del Trabajo (2014) Ord. No 3406/054, disponible en: http://www.dt.gob.cl/legislacion/1611/ w3-article-96717.html [fecha de vista 10 de marzo de 2015]).

80 VALDÉs (1992) pp. 31-32. En similar sentido: MANGARELLI (2014) p. 118: "El poder disciplinario que el contrato de trabajo asigna al empleador puede ser visto como una consecuencia del derecho de dirección. Si el empleador tiene el derecho de impartir órdenes en la realización del trabajo y de controlar el cumplimiento de las mismas, puede entenderse que también se le haya reconocido el derecho de aplicar sanciones en caso de incumplimiento de las órdenes". 
Raúl Fernández Toledo / Precisiones sobre el poder disciplinario del empleador

poderes directivo y disciplinario son componentes de una misma realidad, identificando al poder disciplinario como la última fase en la ejecución del poder directivo y, en consecuencia, un mero elemento adicional ${ }^{81}$. En la doctrina nacional, igualmente existen autores que incluyen el poder disciplinario dentro del poder de dirección ${ }^{82}$.

En nuestra opinión, no obstante, las conexiones que puedan existir entre el poder de dirección y el poder disciplinario y elementos en común, como titularidad del poder, destinatarios de los mismos, fin último, son distintos y autónomos, esencialmente en cuanto a su objeto, no pudiendo subsumirse uno bajo el otro. El poder disciplinario tiene reglas diferentes y un objeto diferente, que no le permite subsumirse bajo el poder de dirección. Por tanto, el poder de dirección no comprende las facultades sancionadoras del empleador ${ }^{83}$. Opinión también sostenida por un sector de la doctrina nacional ${ }^{84}$.

Si bien, ambos poderes se dirigen a tutelar el interés del empleador, por ello su conexión, tienen un campo de actuación diverso. El empleador sólo recurrirá al ejercicio del poder disciplinario cuando las medidas directivas no sean idóneas o suficientes para organizar la empresa, debido, a la concurrencia de un incumplimiento laboral por parte del trabajador ${ }^{85}$. El poder disciplinario queda supeditado a la eficacia del poder de dirección, de manera que solamente entrará a actuar cuando este último ha resultado quebrantado o sus mecanismos son insuficientes para mantener el orden en la empresa. Se trata de un derecho de última ratio de que goza el empleador, que precisa de un incumplimiento laboral, para poder ser ejercicio. Como consecuencia de ello, se deben observar diversos principios que restringen este poder sancionador, como lo son los principios de tipicidad, non bis in ídem, de proporcionalidad, entre otros.

\section{RESPONSABILIDAD DISCIPLINARIA Y RESPONSABILIDAD CONTRACTUAL}

Los orígenes del poder disciplinario se sitúan en el sistema de producción centrado en las fábricas, habida cuenta:

"El proceso de surgimiento y de consolidación de la producción en fábrica es, entre otras cosas y básicamente, el proceso de instauración de un nuevo sistema de disciplina en el trabajo. Con la generalidad del trabajo asalariado como sistema socialmente imperante de trabajo, que se produce tras la revolución francesa y la consiguiente aparición de la sociedad capitalista, se hacía necesario establecer una nueva disciplina de trabajo, adaptada a las nuevas circunstancias y que sustituyese, por tanto, a la disciplina característica de los sistemas anteriores de esclavitud o servidumbre" (Durán, 1979, p. 6).

$81 \quad$ Cruz (2005) p. 237; Martín (1983) pp. 142-143.

\$2 Gajardo (2014) p. 20: "Son inherentes al poder de dirección la potestad disciplinaria, que surge ante el incumplimiento por parte del trabajador de las órdenes e instrucciones que el empleador le imparte y la potestad reglamentaria, con la posibilidad de traducir tales órdenes e instrucciones en reglamentos internos, instructivos y códigos de conducta".

83 Montoya (1965) p. 113; Román (1992) pp. 117 y 119-121; Morato (2011) pp. 46-47; Poquet (2013) p. 32: "la facultad disciplinaria no forma parte del poder de dirección, sino que constituye una facultad con autonomía propia, diferente de la del poder de dirección, aunque íntimamente ligada al mismo, pudiendo sostenerse que forman dos caras de una misma moneda, para cada una con un régimen jurídico diferente y con sustantividad y autonomía propia. Por tanto, la relación entre el poder de dirección y el disciplinario es complementaria, pues éste sirve de apoyo al de dirección, y en cierta manera, al de vigilancia y al de control".

81 En este sentido: IRUReTa (2013) pp. 401-409.

85 Terradillos (2004) p. 19. 
La insuficiencia en esta materia de los mecanismos civiles de resolución por incumplimiento y de la indemnización por daños provocó la recepción del sistema sancionador fundado en el poder disciplinario ${ }^{86}$, que persigue mantener la organización productiva y disciplina en el trabajo. La estructura de la empresa:

"Cuando alcanza ciertas dimensiones, de múltiples relaciones y niveles jerárquicos, hace inadecuado el uso del puro mecanismo contractual de la resolución del vínculo como reacción frente al incumplimiento de la otra parte [...]; inadecuado porque la resolución del contrato es un recurso extremo e irreversible al que sería excesivo acudir para reaccionar frente a los incumplimientos leves que con gran frecuencia se dan en el curso de las relaciones de trabajo [...] De igual manera, la atribución de meras consecuencias indemnizatorias resulta insuficiente respuesta frente al incumplimiento del trabajador, tanto por la normal debilidad patrimonial de éste [...] como por la complicación que supondría para el empresario exigir judicialmente tal indemnización, previa prueba del incumplimiento laboral y del daño por él producido" (Montoya, 2014, pp. 367-368).

El empleador cuando ejerce el poder disciplinario no busca reparar el daño que le puede causar el incumplimiento laboral, sino que castiga simplemente la ilicitud de la conducta del trabajador. Incluso más, la existencia del daño no forma parte de la falta laboral, pudiendo, por tanto, no concurrir y sancionarse la conducta del trabajador, al infringir obligaciones y prohibiciones laborales lícitamente impuestas. Tal circunstancia conduce a calificar las sanciones disciplinarias como verdaderas penas privadas, distintas a los remedios civiles que se activan en caso de incumplimiento de obligaciones contractuales. Es por ello que se debe excluir la homologación de la sanción disciplinaria a la cláusula penal del artículo 1537 del Código Civil, la cual si bien se le ha calificado de pena privada, se debe estipular por las partes en el contrato respectivo, cumpliendo, a la vez, una función de garantía de la obligación contractual y de avaluación convencional de perjuicios derivado de un incumplimiento contractual.

La sanción disciplinaria descansa más en la idea de castigo que en la de resarcimiento, imponiendo el empleador las sanciones de manera unilateral sin intervención previa de un juez, como autotutela privada ${ }^{87}$. El empleador cuando ejerce el poder disciplinario no busca reparar el daño que le pudo haber causado el incumplimiento del trabajador, sino castigar el mismo. Lo que revela que la responsabilidad disciplinaria es distinta a la responsabilidad contractual, desde que esta última tiene lugar cuando se incumple una obligación contractual que le causa perjuicios al acreedor, buscando reparar el daño que le ha causado el incumplimiento. Además, la responsabilidad disciplinaria no necesariamente procede por un incumplimiento contractual, sino que tiene lugar también cuando se infringen normas reglamentarias contempladas en el reglamento interno, lo que conduce a acrecentar las diferencias entre ambos sistemas de responsabilidad.

Los diferentes objetivos entre la responsabilidad disciplinaria y la responsabilidad contractual determina que puede coexistir la imposición de una sanción disciplinaria y la indemnización por daños. Es así, que existe cierta uniformidad de opinión en la doctrina sobre la acumulabilidad del remedio disciplinario con aquel resarcitorio, debido a que el incumplimiento laboral puede tener un carácter pluriofensivo, determinando la posible distinta reacción a la infracción laboral

\footnotetext{
Fernández - Costales (2005)p. 40; Cruz (2010) p. 217.

87 Rodríguez (2008) p. 21.
} 
Raúl Fernández Toledo / Precisiones sobre el poder disciplinario del empleador

-incumplimiento contractual, disciplinario y civil- resarcitorio. Mientras la reacción disciplinaria prescinde totalmente de una finalidad restitutoria o reparatoria, persiguiendo a través de una sanción de carácter eminentemente aflictivo o disuasivo, una forma de reafirmación pro futuro del orden organizativo turbado con la falta laboral ${ }^{88}$, la reacción civil persigue una reparación civil del daño causado con el incumplimiento contractual.

En el plano de la función asignada a la pena disciplinaria, es el lugar en que mayormente se advierte la distancia con la sanción civil - resarcitoria, por cuanto la sanción disciplinaria funciona, a la vez, con un carácter aflictiva en contra del incumplimiento, y también en carácter intimidatoria y preventiva, siendo una garantía de la disciplina y de las reglas de conducta de la organización empresarial $^{89}$; por tanto, existe una cierta analogía entre la sanción disciplinaria y aquella penal, que sólo queda en eso, no siendo equivalentes, presentando notas características diferenciadoras, destacando los diversos bienes tutelados (la sanción disciplinaria protege los intereses del empleador) y la imposibilidad por la normativa disciplinaria de crear delitos, siendo tal prerrogativa reservada al legislador ${ }^{90}$.

Al ser compatible la responsabilidad disciplinaria y contractual no se vulnera el principio non bis in idem, porque las formas de hacer efectiva la responsabilidad del trabajador son distintas y este principio sólo se considera a efectos del ejercicio reiterado del poder disciplinario sobre una misma falta laboral ${ }^{91}$.

\section{REGULACIÓN JURÍDICA ACTUAL DEL PODER DISCIPLINARIO}

El poder disciplinario encuentra su justificación en los mismos preceptos constitucionales que el poder de dirección, lo que encuentra su razón de ser en que ambos persiguen tutelar el interés del empleador. Si bien la Constitución Política no se ocupa directamente ni del poder disciplinario ni del poder de dirección, incluye varios preceptos en los que puede encontrarse fundamento para el poder disciplinario. Así, se tiene el artículo $19 \mathrm{~N}^{\circ} 21$, que garantiza a todas las personas el derecho a desarrollar cualquier actividad económica, y el $\mathrm{N}^{\circ} 24$ del mismo precepto, que regula el derecho de propiedad.

La doctrina nacional mayoritaria fundamenta el poder disciplinario en el artículo $19 \mathrm{~N}^{\circ} 21$ de la Constitución Política ${ }^{92}$. Conclusión que resulta acertada, puesto que si la libertad económica supone la posibilidad de constituir empresas y organizar la actividad empresarial, permitiéndole al empleador organizar la producción de los bienes y servicios, necesita para ello del poder de dirección. Sin embargo, este poder quedaría sin sentido si no tuviera el apoyo del poder disciplinario, el cual permite al titular de la empresa asegurar jurídicamente su autoridad y el cumplimiento de sus órdenes y mandatos con el propósito de alcanzar el objetivo empresarial ${ }^{93}$. De este modo, ambos poderes se configuran como necesarios e indispensables para el correcto funcionamiento de la empresa, sin los cuales sería incongruente hablar de libertad económica.

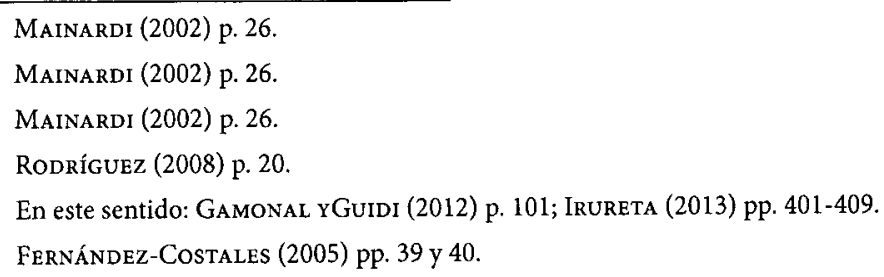


Parte de la doctrina nacional lo fundamenta no sólo en la garantía de la libertad de desarrollar cualquier actividad económica sino también en el derecho de propiedad ${ }^{94}$. Lo que también se comparte, debido a que el hecho que el empleador arriesgue sus bienes en el desarrollo de una actividad económica en que necesita de trabajadores, hace indispensable que le asistan los poderes de dirección y disciplinario, para evitar perjuicios a su propiedad o evitar que se vuelvan a cometer conductas atentatorias contra la misma. En igual sentido se pronuncia la Dirección del Trabajo, al concluir que "el sistema jurídico dota al empleador de lo que la doctrina llama el poder de dirección y de disciplina [...] que de alguna manera es manifestación de los derechos constitucionales de propiedad y de la libertad para desarrollar cualquier actividad económica"95. Es así, como el poder disciplinario encuentra fundamento constitucional en el artículo 19 números 21 y 24 de la Constitución Política, sustentándose tanto en la libertad de empresa como en el derecho de propiedad, que se complementan mutuamente para erigirse en el sustento constitucional de este poder del empleador ${ }^{96}$.

En la doctrina española e italiana, también, se ha fundamentado el poder disciplinario en las normas constitucionales que consagran la libertad de empresa y el derecho de propiedad, ordenamientos jurídicos en que, al igual, que en el ordenamiento nacional, la Constitución no reconoce el derecho del empleador a imponer sanciones a los trabajadores que incurren en incumplimientos laborales. Tratándose de España, se fundamenta el poder disciplinario en dos preceptos de la Constitución principalmente, en el artículo 38, que regula la libertad de empresa, y en el artículo 33, que consagra el derecho de propiedad ${ }^{97}$. Por su parte, en Italia se fundamenta en el artículo 25 de la Constitución Política el poder sancionador del empleador, disposición que garantiza a todas las personas la libertad de empresa ${ }^{98}$. Ambos ordenamientos jurídicos, que luego en normas de rango legal regulan el poder disciplinario.

Descendiendo a la normativa inferior, el régimen legal de la facultad disciplinaria del empleador en el ordenamiento jurídico nacional se contiene actualmente en su vertiente sustantiva en los artículos 5 inciso $1^{\circ}, 153,154 \mathrm{~N}^{\circ}$ s 5, 9, 10 y 160 del Código del Trabajo y, en su vertiente procesal, en los artículos $154 \mathrm{~N}^{\circ}$ s 11 y 12,157, 168, 174 y 489 del mismo Código. Además, respecto del procedimiento de investigación y sanción por denuncias por acoso sexual cabe aplicar los artículos 211-A al 211-E del Código del Trabajo. Tratándose de las obligaciones y prohibiciones de higiene y seguridad en el trabajo que deben observar los dependientes como las sanciones que corresponde aplicar por su contravención, destacan los artículos 14, 18, 19 y 20 del Decreto Supremo $\mathrm{N}^{\circ} 40$, de 1969, del Ministerio del Trabajo y Previsión Social, sobre Prevención de Riesgos Laborales, y el artículo 67 de la Ley $N^{\circ} 16.744$ sobre Accidentes del Trabajo y Enfermedades Profesionales. Siendo esos los preceptos principales que regulan el poder disciplinario, sin perjuicio de normas legales y reglamentarias especiales que son aplicables a empresas de ciertas áreas de la economía.

\footnotetext{
94 Lizama (2003) p. 80.

95 Dirección del. Trabajo (1995) Ord. No 8005/323, disponible en: http://www.dt.gob.cl/legislacion/1611/w3-article-96717. html [fecha de vista 10 de marzo de 2015]; Dirección Del Trabajo (1996) Ord. No 287/14, disponible en: http://www.dt.gob.cl/ legislacion/1611/w3-article-96717.html [fecha de vista 10 de marzo de 2015]; Dirección DEL Trabajo (2002) Ord. N² 2856/162, disponible en: http://www.dt.gob.cl/legislacion/1611/w3-article-96717.html [fecha de vista 10 de marzo de 2015].

96 Fernández (2014a) pp. 146-147.

97 En este sentido: Rivero (1986) pp. 23-36; Castro (1993) p. 33; Terradillos(2004) pp. 14-15; Poquet (2011) pp. 31 -32.

98 FerRante (2012), p. 7.
} 
Raúl Fernández Toledo / Precisiones sobre el poder disciplinario del empleador

Si se observa el contenido de los preceptos legales antes señalados se comprobará que el Código del Trabajo no contiene una regulación exhaustiva del poder disciplinario, pero sí reconoce expresamente al empleador la facultad de sancionar los incumplimientos laborales del trabajador y establece el tipo de sanciones que puede aplicar (artículos $154 \mathrm{~N}^{\circ} 10$ y 160 del Código del Trabajo). Al mismo tiempo, encomienda al reglamento interno la labor de establecer las obligaciones y prohibiciones a que están sujetos los trabajadores cuando se encuentran presentes en la empresa (artículos 153 y $154 \mathrm{~N}^{\circ} 5$ del Código del Trabajo), la regulación de las sanciones que puede aplicar el empleador como consecuencia de las infracción de las obligaciones y prohibiciones reglamentarias (artículo $154 \mathrm{~N}^{\circ} 10$ del Código del Trabajo), el procedimiento a que se someterá la aplicación de las sanciones que se regulan en el reglamento interno (artículo $154 \mathrm{~N}^{\circ} 11$ del Código del Trabajo) y el procedimiento a que se someterán y las medidas de resguardo y sanciones que se aplicarán en caso de denuncias por acoso sexual (artículo $154 \mathrm{~N}^{\circ} 12$ del Código del Trabajo). Por su parte, el Decreto Supremo $\mathrm{N}^{\circ} 40$, se remite el reglamento de higiene y seguridad en el trabajo (que es obligatorio en toda empresa), a fin de que éste establezca las obligaciones y prohibiciones en materia de seguridad que deben observar los trabajadores (artículos 18 y 19 del Decreto Supremo 40) y las sanciones por su contravención (artículo 20 del Decreto Supremo 40), aspecto este último que es reiterado en el artículo 67 de la Ley $\mathrm{N}^{\circ} 16.744$.

Las normas legales y reglamentarias antes indicadas constituyen la configuración legal básica del poder disciplinario, especialmente, tratándose de las sanciones laborales conservativas, que son las que pueden establecer el reglamento interno y el reglamento de higiene y seguridad, y que puede imponer el empleador por infracciones a las obligaciones y prohibiciones establecidas en los mismos. Si bien no conforman una regulación exhaustiva, sí recogen las claves del régimen jurídico de la facultad disciplinaria, como son, la determinación de las faltas y sanciones, la forma que han de adoptar éstas últimas y el sistema de revisión judicial y administrativo de las sanciones impuestas por el empleador, dependiendo de la sanción impuesta. Por tanto, se limita a fijar unas pautas de regulación, remitiéndose al reglamento de higiene y seguridad y al reglamento interno para que regulen las obligaciones y prohibiciones laborales, las sanciones y el procedimiento que debe observarse para aplicarlas. Remisión que es especialmente relevante tratándose de las sanciones conservativas, las cuales solamente se pueden aplicar si los incumplimientos que pueden ser castigados con una de ellas y la sanción misma se encuentran establecidos en el reglamento interno y/o en el reglamento de higiene y seguridad en el trabajo, de lo contrario, no existe posibilidad de imponerse. No ocurre lo mismo con el despido disciplinario, donde las causas y formalidades se encuentran reguladas por la ley misma (artículos 160 y 162 del Código del Trabajo), no existiendo remisión a ninguna otra norma reglamentaria.

La remisión a la normativa reglamentaria tiene importantes repercusiones, porque el empleador no sólo valora las infracciones y decide las sanciones por sí mismo, sino que, tratándose de las sanciones conservativas de la relación de trabajo, también las establece unilateralmente, puesto que es él quien elabora el reglamento interno, existiendo solamente un control de parte de la parte trabajadora, los órganos sindicales y los órganos del Estado competentes (artículo 153 del Código del Trabajo). Lo mismo ocurre con el reglamento interno de seguridad e higiene en el trabajo, desde que el empleador lo elabora unilateralmente, sin perjuicio que el Servicio Nacional de Salud puede revisar su texto e introducir innovaciones cuando le estime conveniente y, además, debe someterlo a consideración del Comité Paritario de Higiene y Seguridad en la forma dispuesta por el artículo 15 del Decreto Supremo $\mathrm{N}^{\circ} 40$.

Aunque las normas legales y reglamentarias pueden parecer escasas, de su lectura no puede menos que concluirse que con las mismas el Código del Trabajo y su normativa complementaria 
está reconociendo y limitando un poder del empleador, al condicionar su ejercicio a una previa regulación de las faltas y sanciones conservativas en el reglamento interno. Por lo demás, solamente puede establecer en el reglamento interno e imponer determinadas sanciones conservativas. De esta forma, el Código del Trabajo proporciona una efectiva cobertura legal al poder disciplinario, respetando el principio de legalidad. No se desvirtúa este principio con el hecho que la tipificación de las obligaciones y prohibiciones laborales y de sanciones laborales conservativas sea encomendada a otras normas de rango inferior, debido a que ello es así porque la propia ley lo permite y la normativa reglamentaria.

La posibilidad de imponer válidamente sanciones conservativas de la relación de trabajo depende de la existencia de un reglamento interno en la empresa y/o de un reglamento interno de seguridad e higiene en el trabajo, de que en los mismos se establezcan dichas sanciones como también las faltas que pueden ser castigadas con una sanción conservativa, pues de no existir en el reglamento interno y/o en el reglamento interno de seguridad e higiene en el trabajo la regulación previa de las sanciones conservativas, el empleador sólo podrá imponer al trabajador infractor el despido disciplinario, siempre y cuando se configure alguna de las causales del despido reguladas en el artículo 160 del Código del Trabajo. Dicha omisión no puede ser suplida o complementada con la negociación colectiva, desde que de acuerdo al inciso $2^{\circ}$ del artículo 306 del Código del Trabajo no pueden ser objeto de la negociación colectiva la facultad del empleador, de organizar, dirigir y administrar la empresa. De este modo, el poder dirección en sentido amplio, dentro del cual se comprende el poder disciplinario ${ }^{99}$, se encuentra dentro de las materias prohibidas de regulación por instrumentos colectivos de trabajo, existiendo una diferencia sustancial con otros ordenamientos jurídicos, donde la normativa legal se remite a la negociación colectiva para regular las faltas y sanciones laborales, estableciendo los límites y prohibiciones que deben observar los convenios colectivos ${ }^{100}$. Sin embargo, dicha prohibición comprendería solamente la posibilidad de imponer o no sanciones laborales, reservada solamente al empleador, más no la posibilidad de convenir obligaciones y prohibiciones laborales, las que pueden establecerse en un instrumento colectivo de trabajo.

\footnotetext{
99 Asi lo ha sostenido reiteradamente la Dirección del Trabajo, al concluir "que en relación con las atribuciones de mando, dirección y administración de la empresa, que corresponden al empleador, dentro de las cuales estaría implicita la potestad disciplinaria y sancionadora, precisa que ellas se pueden traducir solamente en las medidas de sanción que contempla el Código del Trabajo, y que se hayan establecido en el Reglamento Interno de Orden, Higiene y Seguridad de la empresa, para el caso de infracción al mismo por parte del trabajador". En este sentido: Dirección del Trabajo (1987) Ord. N 2084/104, disponible en: http://www.dt.gob.cl/legislacion/1611/w3-article-96717.html [fecha de vista 10 de marzo de 2015]; DiRECCIÓN DEL TRABAJO (2001) Ord. No 3659/0180, disponible en: http:/www.dt.gob.cl/legislacion/1611/w3-article-96717.html [fecha de vista 10 de marzo de 2015]. En similares términos: Dirección del Trabajo (2002) Ord. No 2856/162, disponible en: http://www.dt.gob. $\mathrm{cl} /$ legislacion/1611/w3-article-96717.html [fecha de vista 10 de marzo de 2015], que señala en lo pertinente: "al empresario le es reconocido el ejercicio de una serie de facultades o prerrogativas que tienen por objeto el logro del referido proyecto empresarial en lo que al ámbito laboral se refiere, y que se traducen en la libertad para contratar trabajadores, ordenar las prestaciones laborales, adaptarse a las necesidades de mercado, controlar el cumplimiento y ejecución del trabajo convenido, y sancionar las faltas o los incumplimientos contractuales del trabajador. Estas facultades, responden a lo que genéricamente se denomina poder de dirección -comprendiendo en este concepto amplio tanto el poder de dirección strictu sensu como el disciplinario".

100 El artículo 58.1 del Estatuto de los Trabajadores Español, se remite al convenio colectivo, al disponer: "los trabajadores podrán ser sancionados por la dirección de las empresas en virtud de incumplimientos laborales, y de acuerdo con la graduación de faltas y sanciones que se establezcan en las disposiciones legales o en el convenio colectivo que sea aplicable".
} 


\section{CONCLUSIONES}

Respecto de la configuración dogmática del poder disciplinario del empleador se pueden formular las siguientes observaciones:

$1^{\circ}$ El poder disciplinario tiene un fundamento heterónomo, que reside en el contrato individual de trabajo y en la ley. En nuestra concepción actual del Derecho del Trabajo no tienen cabida la fundamentación contractual y la fundamentación institucional del poder disciplinario.

$2^{\circ}$ Tiene la naturaleza jurídica de autotutela privada de que está dotado el empleador, al reunir todos los elementos configuradores de la autotutela, los que se erigen en verdaderos límites del poder disciplinario, todas vez que deben ser observados por el empleador si pretende no desnaturalizar su poder ni menos ser cuestionado por el trabajador y sancionado por los órganos del Estado que tienen competencia para controlar la legalidad y el mérito de los actos manifestación de dicha autotutela.

$3^{\circ}$ Tiene como primera finalidad evitar que los trabajadores cometan faltas laborales, lo que se logra a través de la tipificación previa de las obligaciones y prohibiciones laborales que deben observar los trabajadores, de las faltas laborales y sanciones de que pueden ser objeto si incurren en una falta laboral. Luego, si el trabajador comete una falta laboral y se impone una sanción disciplinaria, cumple una función aflictiva - al ser un verdadero castigo la sanción disciplinaria -, una función preventiva general, respecto de los restantes trabajadores, y una función preventiva especial, respecto del trabajador sancionado, si la sanción es conservativa. Esto último con el fin que enmienden su conducta en el futuro.

$4^{\circ}$ El poder disciplinario es distinto al poder de dirección. Si bien ambos tienen como titular al empleador y tienen como finalidad última garantizar el éxito de la actividad empresarial en un ámbito de orden y disciplina en la organización empresarial, tienen un objeto distinto. El poder disciplinario garantiza la efectividad del poder de dirección, al permitir al empleador sancionar al trabajador que no ha observado las órdenes, obligaciones, prohibiciones que le impartió en virtud del poder de dirección.

$5^{\circ} \mathrm{El}$ poder disciplinario no tiene como finalidad resarcir el daño causado por el trabajador mediante una falta laboral, sino imponer un castigo, una pena al infractor. De ahí, que sea compatible la responsabilidad disciplinaria laboral y la responsabilidad civil contractual cuando una falta laboral ocasiona un perjuicio al empleador, no resultando vulnerado el principio non bis in ídem, que constituye uno de los límites del ejercicio del poder disciplinario.

Trabajo recibido el 11 de mayo y aprobado el 9 de julio de 2015

\section{BIBLIOGRAFÍA}

Bourie, Enrique (2006): Tratado de responsabilidad extracontractual. (Santiago, Editorial Jurídica de Chile).

BigliazziGeri, Lina (1971): Profili sistematici dell" autotutelaprivata. (Milano, Giuffé).

BrÉGou, Pierre (2012): Le pouvoir disciplinaire de l'employeur. (París, Editions Liaisons).

CarCelén García, Javier (2001): Faltas y sanciones: el expediente disciplinario en la empresa. (Madrid, Fundación Confemetal).

Castro Arguelles, María Antonia (1993): El régimen disciplinario en la empresa. Infracciones y sanciones laborales. (Pamplona, Aranzadi). 
Congeduti, Mara (2011): "Il Procedimentodisciplinari: elementi, principi e regole", en: Pedrazzoli, Mario (a cura), Licenziamenti e sanzioni nei rapporti di lavoro. (Padova, CEDAM) pp. 5-63.

Cruz Villalón, Jesús (2005): "Poder de dirección y nuevas estructuras empresariales", en: Escudero Rodríguez, Ricardo (coordinador), El poder de dirección del empresario: nuevas perspectivas (Madrid, La Ley) pp. 217-245.

Cruz Villalón, Jesús (2010): Compendio de derecho del trabajo. Tercera edición. (Madrid, Tecnos, tercera edición).

DAGNINo, Antonio (1983): Contributo allo studio dell" autotutelaprivata.(Milano, Giuffré).

Diez Picazo, Luis; Gullón, Antonio (2004): Sistema de derecho civil. Volumen I. Introducción. Derecho de la Persona. Autonomia Privada. Persona Jurídica. (Madrid, Tecnos, undécima edición).

Durán López, Fernando (1979): "Las garantías de cumplimiento de la prestación laboral: el poder disciplinario y la responsabilidad contractual del trabajador", Revista Politica Social, N 123, pp. 5-62.

FernándeZ-Costales MuñIZ, Javier (2005): Poder disciplinario empresarial y proceso especial de impugnación de sanciones. (Oviedo, Consejo Económico y Social del Principado de Asturias).

Fernández López, María Fernanda (1991): El poder disciplinario en la empresa. (Madrid, Editorial Civitas S.A.).

FERNÁNDEZ TOLEDO, Raúl (2014a): “La Configuración del poder disciplinario del empleador en el ordenamiento laboral nacional", en: Henríquez, Ian (coordinador), Estudios de Regulación Empresarial (Santiago, LegalPublishing Thomson Reuters) pp. 135-197.

Fernández Toledo, Raúl (2014b): "Límites del poder disciplinario del empleador. Principios non bis in idem y de proporcionalidad en la imposición de sanciones laborales", Revista Chilena de Derecho del Trabajo y de la Seguridad Social, vol. 4, Nº 8, pp. 167-175.

FernáNDeZ Toledo, Raúl (2014c): "La inmediatez en el ejercicio del poder disciplinario empresarial: perdón de la causal", Revista Chilena de Derecho del Trabajo y de la Seguridad Social, vol. 5, N 9, pp. 243-258.

FERNÁNDez Toledo, Raúl (2015): "El poder disciplinario del empleador: configuración jurídica de la sanción disciplinaria que puede imponer al trabajador dependiente", Revista de Derecho de la Pontifica Universidad Católica de Valparaiso, vol. XLIV, pp. 423-460.

Ferrante, Vicenzo (2014): "Fondamento e natura del potere disciplinare", en: Mainardi, Sandro (a cura), Il potere disciplinare del datore di lavoro. (Torino, UTET Giuridica) pp. 1-27.

Gajardo Harboe, María Cristina (2014) "La obligación de seguridad", Revista Chilena de Derecho del Trabajo y de la Seguridad Social, vol. 9, № 2, pp. 15-32.

Galgano, Francesco (1990a): Dirittocivile e commerciale. Volume primo. Le obbligazioni e i contrati. Tomo primo. Obbligazioni in generale. Contrati in generale. (Padova, CEDAM).

Galgano, Francesco (1990b): Dirittocivile e commerciale. Volume primo. Le categorie generali. Le persone. La proprietá. (Padova, CEDAM).

Gamonal Contreras, Sergio; Guidi Moggla, Caterina (2012): Manual del Contrato de Trabajo. (Santiago, Editorial LegalPublishing, tercera edición revisada y actualizada).

GARCía DE ENTERRÍA, Eduardo (1974): “La formación histórica del principio de autotutela dela Administración”, Moneda y Crédito, $N^{\circ} 128$, pp. 59-87.

García de Enterría, Eduardo; Fernández, Tomás Ramón (1989): Curso de Derecho Administrativo. Volumen I. (Madrid, Civitas S.A.).

GIL Y GIL, José Luis (1993): Autotutela privada y poder disciplinario en la empresa. (Madrid, Centro de Publicaciones del Ministerio de Justicia).

IrUReTa Uriarte, Pedro (2013): "El núcleo laboral del derecho constitucional a la libertad de empresa", Estudios Constitucionales, ańo $11, \mathrm{~N}^{\circ} 2$, pp. 369-424.

Kahn - Freund, Otto (1983): Derecho y Trabajo. Traducción al castellano y estudio preliminar de Jesús M. Galiana Moreno. (Madrid, Centro de Publicaciones del Ministerio del Trabajo). 
Raúl Fernández Toledo / Precisiones sobre el poder disciplinario del empleador

Lanata Fuenzalida, Gabriela (2010): Contrato individual de trabajo. (Santiago,AbeledoPerrot-LegalPublishing, cuarta edición revisada y actualizada).

Larenz, Karl (1978): Derecho civil. Parte general. Versión castellana de la tercera edición alemana y notas a cargo de Miguel Izquierdo y Macías - Picavea. (Madrid, Editorial Revista de Derecho Privado).

Le Goff, Jacques (2004): Du silence a la parole. Una histoire du droit de travail. (desannées 1830 a nos jours). (Rennes, Ed. PressesUniversitaires de Rennes, segunda edición).

López Áluarez, María (1999): El expediente disciplinario laboral. (Pamplona, Aranzadi).

MaINARd, Sandro (2002): II potere disciplinare nel lavoro privato e pubblico. (Milano, GuiffréEditore).

MaINARDI, Sandro (2012): "Le sanzioni disciplinari conservative del rapporto di lavoro", en: MaInardi, Sandro (a cura), Il potere disciplinare del datore di lavoro(Torino, UTET Giuridica) pp. 89 - 116.

Mangarelli, Cristina (2014): "Derechos del empleador a la organización y dirección de la empresa, y límites", Revista Chilena de Derecho del Trabajo y de la Seguridad Social, vol. 4, No 8, pp. 13-27.

Martín Valverde, Antonio (1983): "El ordenamiento laboral en la jurisprudencia del Tribunal Supremo", Revista Politica Social, $\mathrm{N}^{\circ} 137$, pp. 105-167.

MazziotTr, Fabio (1982): II licenziamento illegittimo. (Napoli,LigouriEditore).

Mazzotta, Oronzo (2011): Diritto del lavoro.(Milano, GịuffréEditore, quartaedizione).

Montoya Melgar, Alfredo (1965): El poder de dirección del empresario. (Madrid, Instituto de Estudios Políticos).

Montoya Melgar, Alfredo (2014): Derecho del Trabajo.(Madrid, Tecnos, trigésima quinta edición).

Monstuschi, Luigi (1973): Potere disciplinare e rapporto di lavoro. (Milano, Giuffré).

Morato García, Rosa María (2011): Derecho de resistencia y ejercicio irregular del poder de dirección. (Granada, Comares).

Olea, Manuel Alonso; Casas Bahamonde, María Emilia (2006): Derecho del Trabajo. (Madrid, Civitas S.A.,24a edición).

Poquet Catalá, Raquel (2011): La actual configuración del poder disciplinario empresarial. (Valencia, Tirant lo Blanch).

Poquet Catalá, Raquel (2013) El actual poder de dirección y control del empresario. (Pamplona, Thomson Reuters Aranzadi).

Rivero Lamas, Juan (1986): Limitación de los poderes empresariales y democracia industrial. (Zaragoza, Secretariado de Publicaciones de la Universidad de Zaragoza).

Rojas Miño, Irene (2013): "Naturaleza jurídica de la indemnización por término de contrato de trabajo en el Ordenamiento Laboral Chileno", Revista de Derecho Pontificia Universidad Católica de Valparaíso, vol. XLI, pp. 107-143.

Romano, Santi (1945): El ordenamiento jurídico. Traducción al castellano de Santiago Martín - Retortillo y Lorenzo Martin - Retortillo. (Madrid, Instituto de Estudios Políticos).

ROMÁN DE LA TORRE, María (1992): El poder de dirección y el contrato de trabajo. (Valladolid, Grapheus).

Rodríguez Rodríguez, Emma (2008): El poder disciplinario y la negociación colectiva. (Granada,Comares).

TerradillosOrmaetxea, Edurne (2004): El poder disciplinario empresarial. Principios y garantias. (Valencia, Tirant lo Blanch).

Toledo Aldunate, Enrique (2006): El poder disciplinario del empleador. Tesis de Licenciatura en Ciencias Juridicas y Sociales. (Valparaíso, Facultad de Derecho Universidad Católica de Valparaíso).

VAldés DaL - RÉ, Fernando. "Poderes del empresario y derechos de la persona del trabajador", en: Aparicio, Joaquín: BAYlos, Antonio (coordinadores), Autoridad y democracia en la empresa (Madrid, Editorial Trotta) pp. 27- 50.

Vennin Domenach, Francoise (1973): Pouvoir ou Droit disciplinaire dans I entreprise privée. (Lyon, Th Lyon II). 


\section{JURISPRUDENCIA JUDICIAL}

Doudchitzky con MerlinTelecommunications Chile S.A. (2013): Primer Juzgado de Letras del Trabajo de Santiago, 5 de agosto de 2013, RIT O - 1641 - 2013 (acción de despido injustificado)Disponible en: http://poderjudicial. d/SITSUPPORWEB/InicioAplicacion.do [fecha de visita 15 de marzo de 2015].

\section{JURISPRUDENCIA ADMINISTRATIVA}

Dirección Del Trabajo (2014) Ord. $\mathrm{N}^{\circ}$ 3406/054, disponible en: http://www.dr.gob.cl/legislacion/1611/w3article-96717.html [fecha de vista 10 de marzo de 2015].

Dirección del Trabajo (2009) Ord. $\mathrm{N}^{\circ} 2210 / 035$, disponible en: http://www.dt.gob.cl/legislacion/1611/w3article-96717.html [fecha de vista 10 de marzo de 2015].

Dirección Del Trabajo (2002) Ord. N² 2856/162, disponible en: htrp://www.dt.gob.cl/legislacion/1611/w3article-96717.html [fecha de vista 10 de marzo de 2015].

Dirección del Trabajo (200I) Ord. $\mathrm{N}^{\circ}$ 3659/0180, disponible en: http://www.dt.gob.cl/legislacion/1611/w3article-96717.html [fecha de vista 10 de marzo de 2015].

Dirección del Trabajo (r996) Ord. $\mathrm{N}^{\circ}$ 287/14, disponible en: http://www.dt.gob.cl/legislacion/1611/w3article-96717.html [fecha de vista 10 de marzo de 2015].

Dirección Del Trabajo (r995) Ord. $\mathrm{N}^{\circ}$ 8005/323, disponible. en: http://www.dt.gob.cl/legislacion/1611/w3article-96717.html [fecha de vista 10 de marzo de 2015].

Dirección del Trabajo (1987) Ord. $N^{\circ}$ 2084/104, disponible en: http://www.dt.gob.cl/legislacion/1611/w3article-96717.html [fecha de vista 10 de marzo de 2015]. 